\title{
Predicting the acoustic exposure of humpback whales from cruise and tour vessel noise in Glacier Bay, Alaska, under different management strategies
}

\author{
Adam S. Frankel ${ }^{1,2, *}$, Christine M. Gabriele ${ }^{3}$ \\ ${ }^{1}$ Marine Acoustics, Incorporated, 4350 N Fairfax Drive, Suite 600, Arlington, VA 22203, USA \\ ${ }^{2}$ Hawai'i Marine Mammal Consortium, PO Box 6107, Kamuela, HI 96743, USA \\ ${ }^{3}$ National Park Service, Glacier Bay National Park \& Preserve, PO Box 140, Gustavus, AK 99826, USA
}

\begin{abstract}
Vessel traffic management regimes intended to protect baleen whales can have unexpected consequences on whale exposure to underwater noise. Using the Acoustic Integration Model, we simulated whale and vessel movements in Glacier Bay National Park (GBNP). We estimated vessel noise exposures to humpback whales Megaptera novaeangliae while varying the number, speed (13 vs. 20 knots [kn]), and timing of cruise ships, and keeping a constant number, speed, and timing of smaller tour vessels. Using calibrated noise signatures for each vessel and the known sound velocity profile and bathymetry of Glacier Bay, we estimated received sound levels for each simulated whale every $15 \mathrm{~s}$ in a $24 \mathrm{~h}$ period. Simulations with fast ships produced the highest maximal sound pressure level (MSPL) and cumulative sound exposure levels (CSEL). Ships travelling at $13 \mathrm{kn}$ produced CSEL levels 3 times lower than those traveling at $20 \mathrm{kn}$. We demonstrated that even in cases where a ship is only a few $\mathrm{dB}$ quieter at a slower speed, CSEL is lower, but the ship's transit may take substantially longer. Synchronizing ship arrival times had little effect on CSEL or MSPL but appreciably decreased cumulative sound exposure time (CSET). Overall, our results suggest that the most effective way to reduce humpback whale acoustic exposure in GBNP is to reduce the numbers of cruise ships or their speed, although adjusting ship schedules may also be beneficial. Marine protected area managers may find these results illustrative or adapt these methods to better understand the acoustic effects of specific vessel management circumstances.
\end{abstract}

KEY WORDS: Acoustic propagation - Vessel noise - Chronic exposure - Management · Cumulative effects · Marine Protected Area

\section{INTRODUCTION}

The effect of vessel noise on marine mammals is an increasing concern worldwide. Quantifying the effects and how they might change under alternative vessel management actions, however, is a substantial challenge. Management decisions are therefore often made in the absence of a quantitative understanding of the implications of a particular management strategy. In this study, we used empirical data on vessel

*Corresponding author: adam.frankel@marineacoustics.com source levels to model and compare the acoustic exposures of humpback whales Megaptera novaeangliae under a variety of vessel operation scenarios in Glacier Bay National Park (GBNP), a marine wilderness area in southeastern Alaska. The National Park Service (NPS) is mandated to manage the number and behavior of vessels operating within the Park to protect GBNP resources, including threatened and endangered species, while affording the public an opportunity to enjoy these same animals. In this

(C) The authors 2017. Open Access under Creative Commons by Attribution Licence. Use, distribution and reproduction are unrestricted. Authors and original publication must be credited. 
study, we used acoustic modeling to cost-effectively explore the effects of vessel management parameters on the underwater sound environment, an approach that is applicable in many marine environments where vessel-generated noise is a concern. GBNP is an ideal place to conduct this work because it is geographically and acoustically isolated, and in light of the Park's long time-series of data on vessel and whale abundance and movement patterns and vessel noise measurements.

Management concerns about the effects of vessels on baleen whales generally center around 2 factors: behavioral disturbance and the death or injury of whales from vessel collisions (i.e. ship strikes). Temporary or permanent hearing loss is theoretically possible in cases of extreme or chronic exposure to loud noises, but is not expected in these conditions. Substantial evidence indicates that vessel speed is an important factor affecting the likelihood and lethality of ship strikes (Laist et al. 2001, Jensen \& Silber 2003, Vanderlaan \& Taggart 2007). Therefore, managers sometimes rely on vessel speed limits to mitigate the risks of ship strikes. GBNP began using vessel course and 10 to $13 \mathrm{knot}(\mathrm{kn})$ speed restrictions to reduce disturbance and ship strike risks to humpback whales in 1979 (36 CFR 13.65, 2001 [CFR: code of Federal Registrations]). It was the first location to use such measures specifically to protect whales. Since 2008, NOAA Fisheries has also used vessel routing and a 10 kn speed limit (50 CFR 224.105, 2011; Federal Register 73:60173) to protect the endangered North Atlantic right whale Eubalaena glacialis from ship strikes in certain areas along the east coast of the US with apparent success (Laist et al. 2014). Likewise, the US Coast Guard, in collaboration with the Channel Islands National Marine Sanctuary, implemented a voluntary $10 \mathrm{kn}$ speed limit within 20 nautical miles (nmi) of the entrances to the ports of Los Angeles and Long Beach in response to a number of ship strike deaths of blue whales Balaenoptera musculus in waters off southern California. These measures seem to have had limited success due to poor compliance (McKenna et al. 2012).

Baleen whale behavioral disturbance by anthropogenic underwater noise has been documented in a variety of cases (Richardson et al. 1995, Parks et al. 2007, Sousa-Lima \& Clark 2008), but predicting the type and severity of disturbance is difficult. Recent efforts to quantify and classify disturbing acoustic stimuli indicate that baleen whales rarely respond to received sound pressure levels at 90 to $120 \mathrm{~dB}$ re $1 \mu \mathrm{Pa}$, but show an increasing probability of avoidance and other behavioral reactions to sound in the
120 to $160 \mathrm{~dB}$ re $1 \mu \mathrm{Pa}$ range (Southall et al. 2007). However, baleen whale response may vary depending on behavioral context, sound source proximity, novelty, and sound pressure level (Ellison et al. 2012). For example, McKenna et al. (2015) found that feeding blue whales exhibited a limited and inconsistent response repertoire during close approaches by large vessels near ship channels off the ports of Los Angeles and Long Beach. Likewise, deep-feeding blue whales showed stronger responses to presentation of anthropogenic noise than other behavioral states (Friedlaender et al. 2016).

The impact of auditory masking of biologically relevant sounds by anthropogenic noise may be as great or greater than overt behavioral responses, constituting a transient and dynamic form of acoustic habitat loss (Clark et al. 2009). Masking is the process by which the audibility of one sound is reduced by the presence of another sound (Moore 1982). The effect can prevent listeners from recognizing or detecting biologically important sounds (Clark et al. 2009, Barber et al. 2010). The biological significance of masking almost certainly varies by species, behavioral context, population size and distribution, as well as other factors. Nevertheless, vessel noise clearly has the potential to mask essential baleen whale communication signals and prevent whales from detecting potential predators (Hatch et al. 2008, Tyack 2008, Clark et al. 2009). The effect of noise on receivers is often assessed using acoustic propagation models that can predict the spatial pattern and extent of sound fields (e.g. Erbe 2002, 2015). However, neither vessel sound sources nor animal receivers are static in time and space. Considering the movements of the sound sources and receivers within a sound field can refine acoustic exposure estimates. Individual-based models can incorporate both movement types and record predicted sound levels at simulated animals throughout an encounter (Frankel et al. 2002, Houser 2006).

Currently, GBNP regulations allow up to 2 cruise ships, 3 tour vessels and 31 smaller charter and private vessels on a daily basis during the June through August summer season (Code of Federal Regulations 13.65). The large cruise ships are passenger vessels weighing $>100$ gross tons ( $t_{;}$US system) and typically carry thousands of passengers, whereas tour vessels are $<100$ gross $t$ and carry up to 149 passengers. Smaller motor vessels range from small outboard engine-powered skiffs and workboats to yachts and fishing vessels with inboard diesel engines. Vessel noise is typically due to engine, propulsion system, and propeller-related noise (Ross 2005). Small craft 
with high-speed engines and propellers generally produce higher frequency noise than large vessels (Erbe 2002, Erbe et al. 2013). Large vessels, including the cruise ships and tour vessels, generate substantial low frequency noise because of their size and their large, low rpm engines and propellers (Arveson \& Vendittis 2000).

GBNP currently imposes a seasonal cap of 153 cruise ships per $92 \mathrm{~d}$ season, such that only an average of 1.7 ships $d^{-1}$ are authorized to enter. Decisions about the number of cruise ship entries are made annually at the discretion of the NPS. This study focused on the acoustic effects of different numbers of cruise ships and different ship operational factors to help inform management decisions on the number, location, density, and speed of ships allowed in GBNP. Tour vessels were included in the model as they are another main source of large vessel traffic. Smaller vessel types can also contribute to underwater noise levels in the region (Kipple \& Gabriele 2003b), but were not included in the model to retain a narrow focus on the vessel class affected by this particular management decision. Furthermore, small craft have lower source levels, with sound spectra shifted toward higher frequencies than larger ships. Consequently, in general, the audible ranges of small vessels are far smaller than those of larger ships, such that small vessels have the potential to affect a single group of whales, whereas larger ships can affect multiple groups simultaneously.

Large vessel traffic contributes substantial amounts of underwater noise to the marine environment, but few quantitative studies in marine protected areas have been attempted (Hatch et al. 2008). One of the issues in studying these systems is that shallow-water acoustic modeling is inherently complex (Jensen et al. 2000). The steep walls of the narrow fjords of Glacier Bay further complicate the matter, creating conditions in which empirical measurements of acoustic propagation are invaluable.

This study evaluated 14 different vessel scenarios created by varying the number, speeds, and times of arrival at the mouth of Glacier Bay for simulated cruise ships. With no more than 2 cruise ships $d^{-1}$ allowed in GBNP, we hypothesized that noise exposures would be greater when 2 ships (rather than 1) are in GBNP. Quantifying that difference can help inform decisions on cruise ship numbers if meaningful differences are found. The effect of ship speed upon acoustic exposure levels is important to quantify because whale management strategies can call for vessel speed limits to reduce the risk of ship strikes as well as underwater noise. Also, although sound signa- ture studies indicate that most ships are quieter at slow speed than they are at higher speeds (Kipple 2002, 2004a,b, Trevorrow et al. 2008), it is unknown whether the cumulative noise exposure from a slower ship is less than that from a faster ship, since the listener is exposed to the noise from a slower ship for a longer duration. Similarly, simulating different ship arrival times allows their effect on maximum and cumulative noise exposures to be quantified and demonstrates how these noise exposures are distributed in time. Synchronous or asynchronous ship arrival times could become part of a vessel management strategy if meaningful differences exist. Although ship scheduling, fuel consumption, stack emissions, and other factors must be weighed alongside the acoustic implications of vessel operations, this quantitative comparison gives managers an objective basis for comparing a range of management options.

The present study is the first attempt to quantify the effect of vessel speed limits and other factors on humpback whale noise exposure in Glacier Bay. These results are applicable to specific management concerns in Glacier Bay; however, the methods developed here are readily applicable to other locations. Moreover, they demonstrate how quantitative acoustic analyses can be used to evaluate management of a marine protected area. By exploring the range of potential outcomes from different management strategies, this work presents a cost-effective method to explore the acoustic aspects of vessel management with the potential to help managers address similar concerns in other marine protected areas.

\section{METHODS}

\section{Acoustic Integration Model}

The Acoustic Integration Model $^{\complement}$ (AIM) is a sophisticated model that can estimate the underwater sound level at a given range and depth from a sound source. It was developed to predict the sound exposure of marine animals from anthropogenic sources (Frankel et al. 2002). The model uses 'animats', which are virtual entities within the AIM that represent both animals and vessels. Vessel movements are programmed by a series of waypoints and are thus deterministic. The model moves whale animats through the 4 dimensions of space and time, according to species-specific rules defining parameters such as swim speed, dive depth, and change in heading. The values of these parameters were taken from literature on humpback whales (Dolphin 1987a,b, 
Baker \& Herman 1989, Gabriele et al. 1996, Dalla Rosa et al. 2008, Witteveen et al. 2008). Received sound levels (terminology is defined later in this section) are periodically estimated at a user-specified time interval. This study used an interval of $15 \mathrm{~s}$. Therefore, the acoustic exposure was estimated at least 2000 times for each animat during each simulation. Each simulation lasted less than $1 \mathrm{~d}$, much less than mean residence times (35 to $66 \mathrm{~d}$ ) for humpback whales in Glacier Bay (GBNP unpubl. data).

\section{Acoustic exposure terminology}

Acoustic exposure, defined as the estimated quantity of sound to which each animat was exposed, was quantified with 2 amplitude metrics: maximum sound pressure level (MSPL) and cumulative sound exposure level (CSEL). The MSPL level indicates the single loudest sound level to which each animat was exposed during the simulation and is reported as a broadband root mean square (RMS) level ( $\mathrm{dB}$ re $1 \mu \mathrm{Pa})$. The CSEL is the sum of all broadband sound received by each receiver from each sound source over the course of a day, normalized to $1 \mathrm{~s}$ duration ( $\mathrm{dB}$ re $\left.1 \mu \mathrm{Pa}^{2}-\mathrm{s}\right)$. The MSPL metric is currently used by the National Marine Fisheries Service (NMFS) acoustic guidelines for Level B (behavioral) harassment (Scholik-Schlomer et al. 2009). For cetaceans, the Level $B$ threshold for continuous sounds is $120 \mathrm{~dB}$, and $160 \mathrm{~dB}$ for intermittent sounds (ScholikSchlomer et al. 2009). However, many investigators acknowledge the importance of sound duration as a determinant of the behavioral response and in predicting physical injury (Southall et al. 2007). Both MSPL and CSEL metrics are employed in the recently adopted acoustic criteria for sound-related injury (NOAA 2016). The permanent threshold shift (PTS) threshold for mysticete whales is estimated at 199 dB CSEL.

When considering the differences in acoustic exposure under different scenarios it is important to remember that decibels use a logarithmic scale. A difference of $6 \mathrm{~dB}$ sound pressure level (SPL) represents a doubling of sound pressure, while a $3 \mathrm{~dB}$ difference in CSEL represents a doubling of sound intensity (because intensity is proportional to squared pressure).
Therefore, small differences in decibel values can indicate large magnitude differences.

Two temporal metrics were introduced to complement the amplitude metrics: mean quiet and mean sound exposure times. These metrics were introduced because the duration of a noise may affect an individual's behavioral response (Ellison et al. 2012). To calculate these metrics, each whale's sound exposure history was plotted over time. Fig. 1 shows an example from 1 run. Quiet times (QTs) are periods when the SPLs are below the threshold, and sound exposure times (SETs) occur when the SPL exceeds a threshold. Multiple instances of QTs and SETs are shown. The summed sound exposure time for each animat is referred to as the cumulative sound exposure time (CSET). The threshold use for these metrics is $110 \mathrm{~dB}$ re $1 \mu \mathrm{Pa}$, which is $10 \mathrm{~dB}$ less than the current NOAA threshold for behavioral disturbance related to continuous noise sources (Scholik-Schlomer et al. 2009) and $8 \mathrm{~dB}$ higher than the maximum ambient noise level reported for Glacier Bay (Kipple \& Gabriele 2003a). Mean QT and SET were calculated for each whale animat for each modeling run. Finally, the mean values across all animats for each run were calculated.

\section{Statistical methods}

All statistical tests were conducted with JMP v.12 (SAS Institute 2015). Dependent variables included MSPL, CSEL, CSET, and QT. Each animat in each simulation was represented by a single value in the

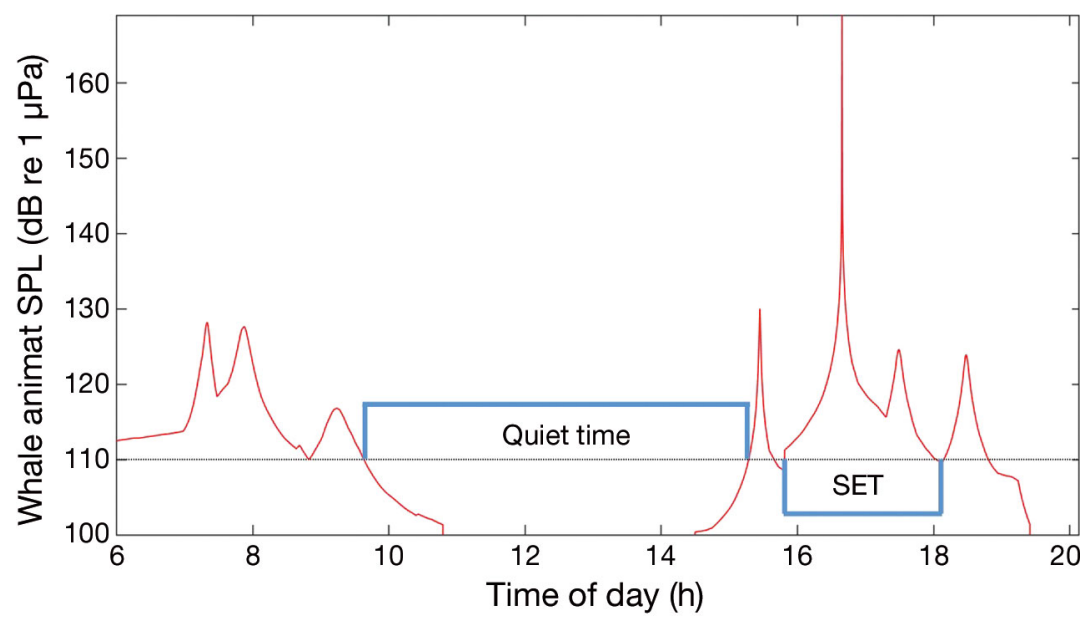

Fig. 1. Graphical depiction of the temporal metrics showing quiet time and sound exposure time (SET). Quiet times are when the received sound pressure level (SPL) is less than the threshold. Conversely, SETs are when the received SPL exceeds the threshold. Individual sound exposure bouts were summed to create the cumulative sound exposure time (CSET) for each animat 
models. Predictor (or independent) variables included the number of cruise ships, cruise ship speed, arrival interval time, and presence of tour boats. All variables were specified as having a continuous distribution except for number of cruise ships (ordinal) and presence of tour boats (categorical). All tests were run using a standard general linear model (GLM). Pairwise comparisons for the numbers of cruise ships were made using least-square means and Student's $t$-tests.

Each analysis included $\sim 1200$ animats for each simulation run. Individual simulation runs represent different treatments (e.g. number and speed of cruise ships). The first analysis presented considered the effect of the number of cruise ships, their speed and the arrival interval time. Thus, results from 8 simulations were combined to produce the dataset for that statistical test that included $~ 9600$ animats.

\section{Physical environment}

AIM requires the user to specify a num-

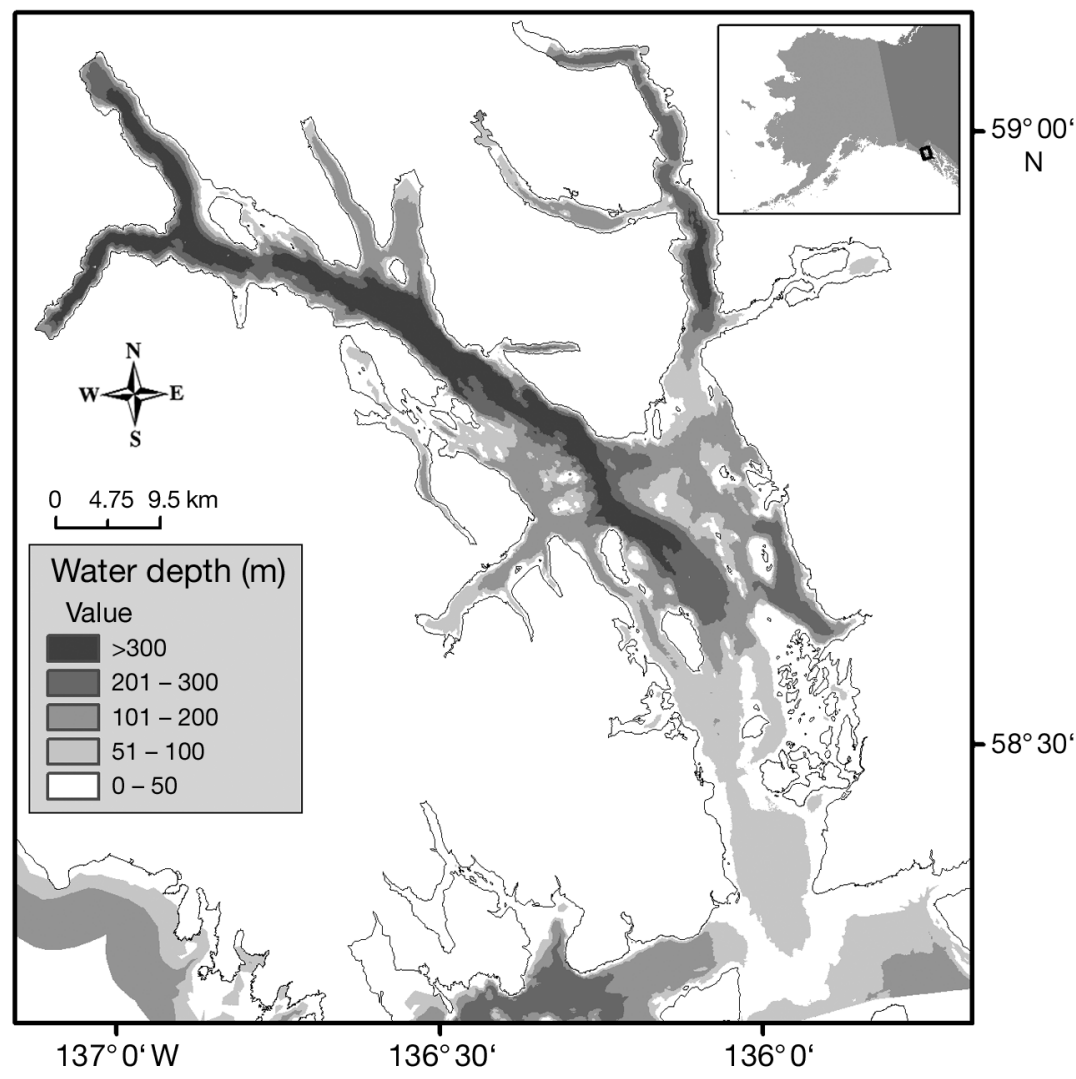

Fig. 2. Water depth in Glacier Bay is shown ber of parameters in order to simulate the physical environment accurately. The first of these is bathymetry, which defines the physical volume through which the animats move (Fig. 2). We used 100 m gridded UTM-8 bathymetry data (Hooge et al. 2004) converted to the Plate Carrée (Geographic) projection for the modeling effort.

Underwater sound propagation is affected by the salinity and temperature profiles in the water column as well as absorption or reflection off the seafloor or the steep walls of the fjords that make up Glacier Bay. The complexity and the dynamic nature of the physical environment make numerical modeling of propagation challenging at best. Therefore a semiempirical acoustic propagation model was used in this study (shown in Fig. 3), based on broadband (100 Hz to $16 \mathrm{kHz}$ ) sound transmission loss measurements made in Glacier Bay (Malme et al. 1982, their Fig. 27). Specifically, the model included spherical spreading $(20 \log \mathrm{R})$ to a range of $100 \mathrm{~m}$ from the sound source at which point it transitions to a $15 \times$ $\log \mathrm{R}$ spreading term. Acoustic absorption was calculated for $100 \mathrm{~Hz}$, because this frequency is typically prevalent in both humpback whale vocalizations and the average frequency spectrum of large commercial vessels. This model was compared with predictions

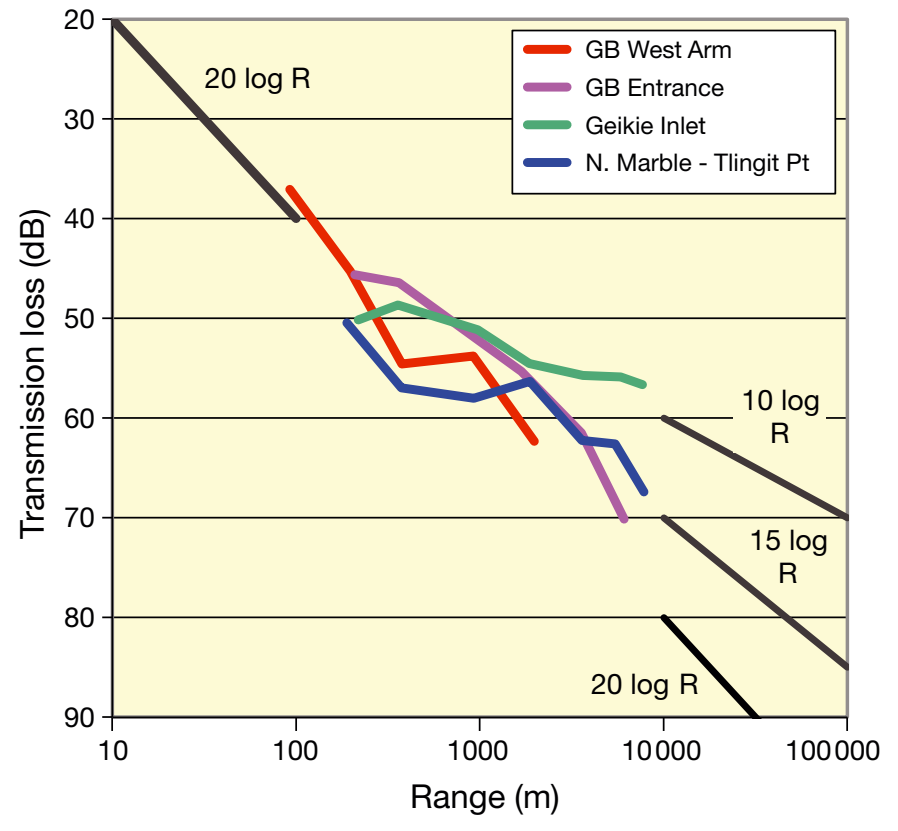

Fig. 3. Underwater sound transmission loss in the study area used in the present study, as measured by Malme et al. (1982). This redrawing of their Fig. 27 shows 4 underwater sound transmission loss measurements within Glacier Bay (GB). Black lines represent simple geometric spreading models 
from the Bellhop computational acoustic propagation model (Porter 1992). There was very good agreement between the 2 models' predictions, indicating that either model could be used with success. The Malme et al. (1982) model was selected for the GBNP AIM modeling effort because it can be applied in shallow water (i.e. depth less than $1 / 4$ of an acoustic wavelength), whereas the Bellhop model cannot always make reliable predictions in shallow water. The model uses broadband source levels for the vessels and reports broadband received levels at the whales' locations. The mean RMS broadband ambient noise reported for Glacier Bay was $84 \mathrm{~dB}$ re $1 \mu \mathrm{Pa}$, with a range that extended from 67 to $102 \mathrm{~dB}$ re $1 \mu \mathrm{Pa}$ (Kipple \& Gabriele 2003a).

\section{Humpback whale animat movement}

Biological parameters, including the initial placement of animats and the rules that define their movement, are critical to realistic estimates of acoustic exposure. The sound level to which a whale is exposed is primarily a function of the whale's depth and range from the vessel (among other parameters), so an accurate representation of a whale's movements is necessary to simulate the 4-dimensional relationship between whales and vessels. AIM whale animat movement parameters were based on measured dive times, dive depths, and movement patterns from published literature (Dolphin 1987b, 1988, Baker \& Herman 1989, Gabriele et al. 1996, Dalla Rosa et al. 2008, Goldbogen et al. 2008, Witteveen et al. 2008, Kennedy et al. 2014) and are summarized in Table 1. Three types of animats representing feeding, foraging, and traveling whales (Fig. 4) were used in the simulations. Whales and vessels were not programmed to approach or avoid each other; therefore, the distance between whales and vessels was determined solely by the course of the vessel and the movement pattern of the whale.

Individual-based models like AIM can also incorporate an 'aversion' or 'avoidance' response to stimuli such as received sound level (Frankel et al. 2002).

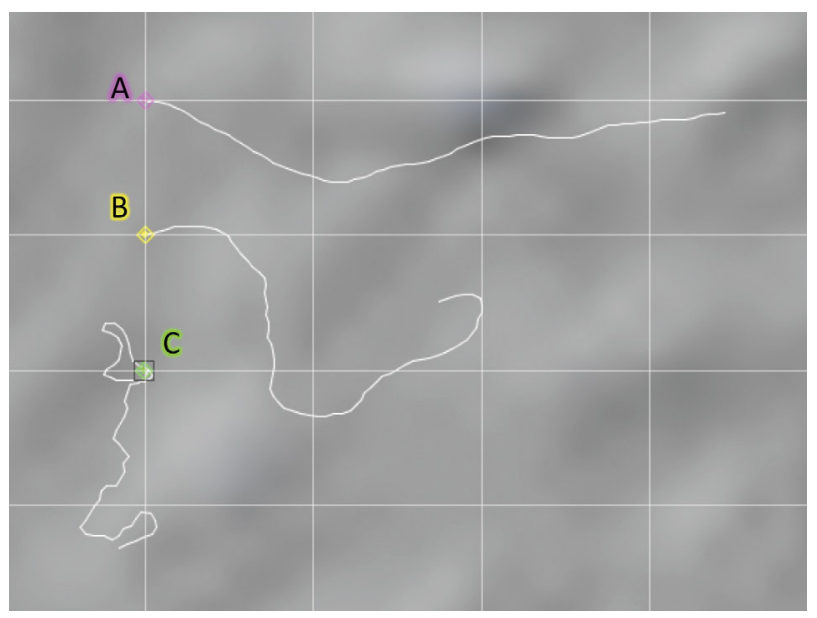

Fig. 4. Animat types A, B, and C, programmed with increasingly large turn angles and progressively shorter times to change course. The resulting linearity indices for these animats were $0.94,0.64$, and 0.39 respectively, with a mean of 0.67; comparable to the observed mean linearity index for humpback whales in Glacier Bay of 0.75 (Baker \& Herman 1989). A traveling whale animat (A) will have a directed path and a low heading-variance and a high linearity index. A searching whale animat (B), searching for a prey patch will have a meandering path and a medium linearity index. A feeding whale animat $(\mathrm{C})$ that has found a prey patch will have a circuitous path as it pursues its prey repeatedly and will therefore have a high heading-variance and a low linearity index

Table 1. Movement parameters for feeding humpback whales used as inputs to the Acoustic Integration Model (AIM). Surface time, dive depth, and swim speed parameters are all stated as min./max.; linearity index is the total distance covered/straight line distance. The A, B, and C designations in the 'Max. change in heading' column refer to the 3 animat types shown in Fig. 4. Blank cells indicate that the respective cell has the same value as the one above

\begin{tabular}{|c|c|c|c|c|c|c|c|}
\hline $\begin{array}{l}\text { Surface } \\
\text { time } \\
(\mathrm{min})\end{array}$ & $\begin{array}{l}\text { Surface } \\
\text { dive } \\
\text { angle }\left(^{\circ}\right)\end{array}$ & $\begin{array}{c}\text { Dive depth }(\mathrm{m}), \\
\text { and \% of time in } \\
\text { each behavioral state }\end{array}$ & $\begin{array}{l}\text { Dive } \\
\text { time } \\
\text { (min) }\end{array}$ & $\begin{array}{l}\text { Max. change in } \\
\text { heading per time period } \\
\text { (angle/turn time) (deg/s) }\end{array}$ & $\begin{array}{l}\text { Linearity } \\
\text { index }\end{array}$ & $\begin{array}{l}\text { Swim } \\
\text { speed } \\
\left(\mathrm{km} \mathrm{h}^{-1}\right)\end{array}$ & $\begin{array}{c}\text { Statistical } \\
\text { distribution of } \\
\text { speed values }\end{array}$ \\
\hline \multirow[t]{9}{*}{$1 / 2$} & \multirow[t]{9}{*}{$75 / 75$} & $10 / 40(75 \%)$ & \multirow[t]{9}{*}{$5 / 10$} & $45 / 300(\mathrm{~A})$ & 0.94 & \multirow[t]{9}{*}{$2 / 10$} & \multirow[t]{9}{*}{ Normal } \\
\hline & & & & $60 / 150$ (B) & 0.64 & & \\
\hline & & & & $90 / 60$ (C) & 0.39 & & \\
\hline & & \multirow[t]{3}{*}{$40 / 100(20 \%)$} & & $45 / 300(\mathrm{~A})$ & 0.94 & & \\
\hline & & & & $60 / 150$ (B) & 0.64 & & \\
\hline & & & & $90 / 60$ (C) & 0.39 & & \\
\hline & & \multirow[t]{3}{*}{$100 / 150(5 \%)$} & & $45 / 300(\mathrm{~A})$ & 0.94 & & \\
\hline & & & & $60 / 150$ (B) & 0.64 & & \\
\hline & & & & $90 / 60(\mathrm{C})$ & 0.39 & & \\
\hline
\end{tabular}


In other modeling exercises, such avoidance has been shown to reduce the received MSPL for animats (Ellison et al. 2016). The primary reason that avoidance responses were not included in these simulations was because real-world animal response to noise is not well understood and likely occurs as a function of social context in addition to sound level (Ellison et al. 2012). By omitting unnecessary speculation about whale avoidance responses, the current work focuses on determining the relative effectiveness of different vessel management options.

\section{Whale animat placement}

Humpback whales within Glacier Bay are found in all water depths $>5 \mathrm{~m}$. Therefore the minimum water depth in the model was set to $5 \mathrm{~m}$ to prevent animats from going ashore. No maximum depth was specified.

Whale animats were randomly distributed throughout Glacier Bay up to $59^{\circ} \mathrm{N}$, but then manually removed from the upper, narrow ends of the fjords because the reported density of animals is low in these regions (Fig. 5). Nevertheless, the

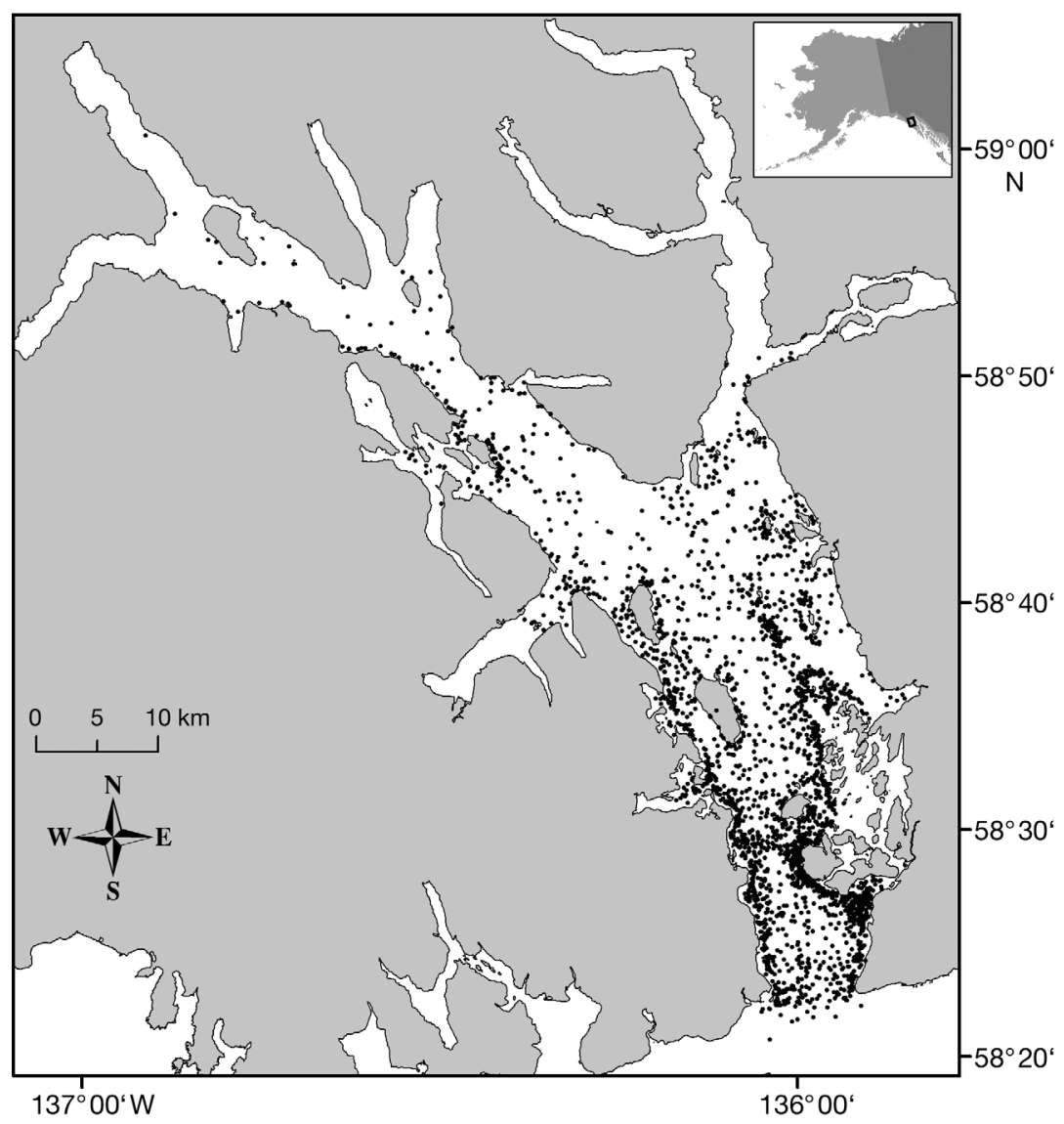

Fig. 5. Humpback whale distribution data in Glacier Bay from 1993 to 2006, showing the concentration of animals in the lower bay programmed movements of some animats allowed them to enter these areas during the simulation. Additional animats were placed below the latitude of $58^{\circ} 40^{\prime} \mathrm{N}$ to reflect the higher whale density normally found in lower Glacier Bay (Neilson \& Gabriele 2006). The nearshore concentration of animals seen in Fig. 5 could not be replicated in the model due to the narrow width and complex bathymetry of Glacier Bay. The starting distribution of a total of 1201 animats is shown in Fig. 6.

\section{Vessel animat tracks and speeds}

Each of the simulations represented an implementation of different values of the vessel predictor variables. Each simulation can be considered a predicted outcome of a different vessel management strategy. A total of 14 different simulations were created to represent all of the combinations of vessel parameters needed for the analysis. The outputs are combined as needed to evaluate the effect of different vessel parameters. The tracks of vessel animats were defined as waypoints (a series of latitude and longitude positions with an associated time value) completing $1 \mathrm{~d}$ voyages that began and ended at or near the mouth of Glacier Bay. Because cruise ships tend to travel on uniform routes in Glacier Bay with only slight variations, the AIM model used a single representative track based on a composite of GPS and automatic identification system (AIS) data collected from transits of several cruise ships. However, tour vessel itineraries and routes are more variable; therefore, the simulations included 3 different tracks that were based on GPS data collected from tour vessels.

The cruise ship and tour vessel tracks were the same in all model simulations (Fig. 6) but the starting time and speed of the cruise ships varied. Cruise ships arrived at the mouth of Glacier Bay at 3 different times in the morning $(06: 00,07: 00$ or $10: 00 \mathrm{~h})$, reflecting actual possible schedules (Fig. 7). Cruise ships were programmed to travel at either 13 or $20 \mathrm{kn}$ with corresponding durations of 750 or $630 \mathrm{~min}$. However, cruise ship animat speeds were adjusted to allow them to go slower to account for the Park Ranger pick-up and drop-off in the lower bay, and for 


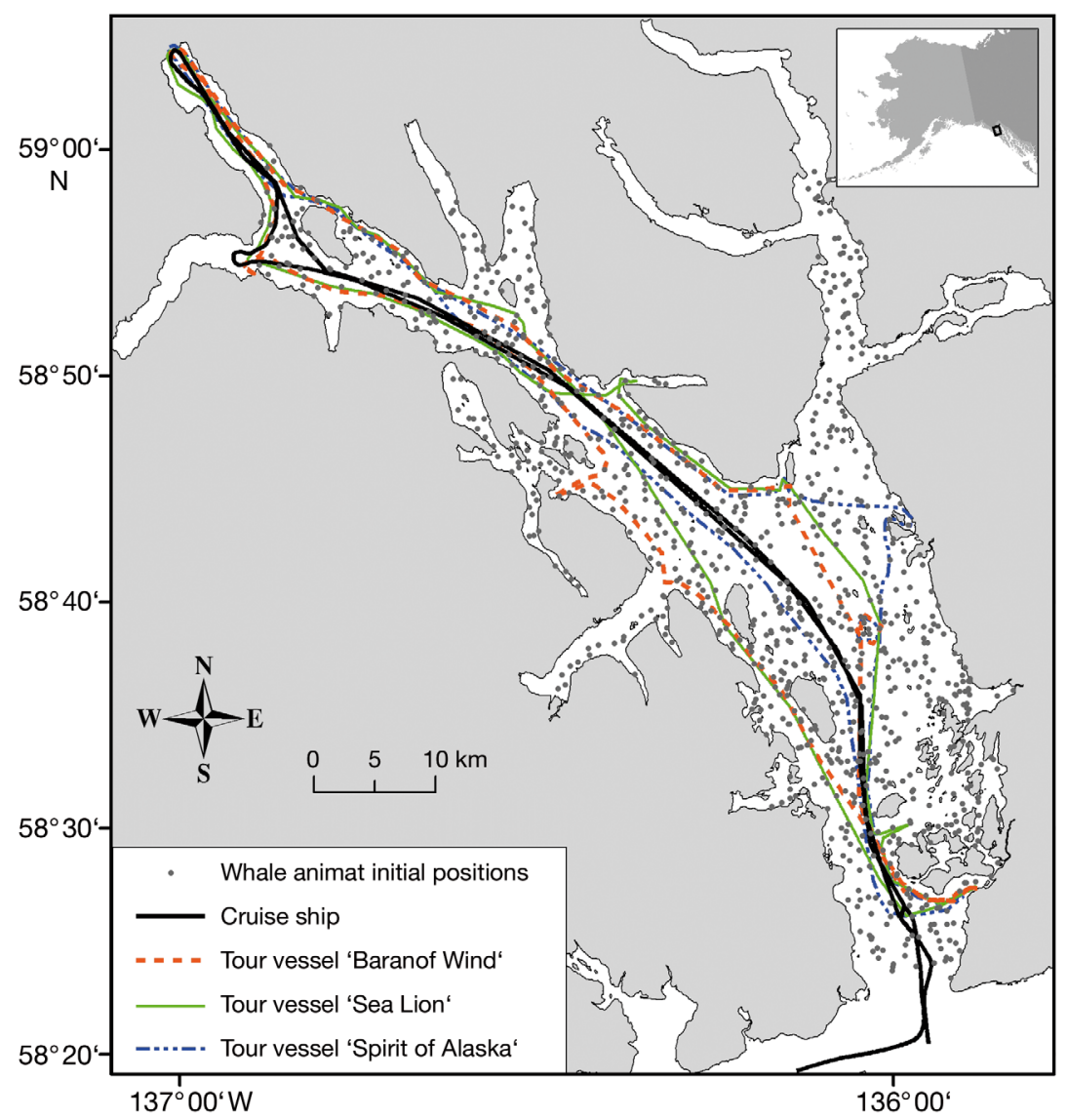

Fig. 6. Tracks of vessels used in the simulations and the initial placement of whale animats showing an increased density of animats in lower Glacier Bay (below $58^{\circ} 40^{\prime} \mathrm{N}$ ) to represent the increased number of animals typically observed in this area sightseeing near the glaciers in the upper bay. These changes reflect actual cruise ship behavior. Tour vessel speed was derived from typical travel speeds of these vessels (Table 2) and ranged from 10.5 to $20 \mathrm{kn}$. The tracks, speed and timing of the 3 tour vessels were the same in all model simulations (Fig. 6).

Additional model runs were conducted to investigate specific questions about cruise ship movements. Following completion of the first 9 simulations, the results were examined and the 2 simulations with the lowest and highest exposures were re-run with no tour (NT) vessels (4NT and 6NT). To examine the effect of cruise ship timing, the additional runs were also repeated without tour boats (1NT, 2NT, 3NT and 6NT). These runs had closely spaced and widely spaced arrival times for both speed classes. One simulation of each type was run, including the selected vessels and $\sim 1200$ whale animats.

\section{Vessel acoustic parameters}

The cruise ships used in the model were large passenger vessels 219 to $293 \mathrm{~m}$ in length and grossing approximately 51000 to $91000 \mathrm{t}$ (Table 2). The tour vessels

Table 2. Source levels of cruise ships and tour vessels. The values used for modeling simulations are shown in bold

\begin{tabular}{|c|c|c|c|c|}
\hline Vessel & $\begin{array}{l}\text { Speed } \\
\text { (kn) }\end{array}$ & $\begin{array}{l}\text { RMS broadband } \\
\text { sound level } \\
\text { (dB re } 1 \mu \mathrm{Pa} \text { at } 1 \mathrm{~m} \text { ) }\end{array}$ & $\begin{array}{l}\text { Gross tonnage/ } \\
\text { passengers }\end{array}$ & Data source \\
\hline \multicolumn{5}{|c|}{ Cruise ships at slower speeds } \\
\hline 'Coral Princess' & 10 & 182.3 & $91627 / 2214$ & Kipple (2004a) \\
\hline 'Norwegian Wind' & 10 & 171.8 & $51309 / 1748$ & Kipple (2002) \\
\hline 'Volendam' & 10 & 186.1 & $61214 / 1432$ & Kipple (2004b) \\
\hline 'Statendam' & 10.8 & 175.8 & $55819 / 1260$ & Kipple (2002) \\
\hline Median & & 179.1 & & \\
\hline \multicolumn{5}{|c|}{ Cruise ships at higher speeds } \\
\hline 'Statendam' & 18 & 178.2 & $91627 / 2214$ & Kipple (2002) \\
\hline 'Norwegian Wind' & 19.2 & 191.9 & $51309 / 1748$ & Kipple (2002) \\
\hline 'Coral Princess' & 20 & 188.2 & $61214 / 1432$ & Kipple (2004a) \\
\hline 'Volendam' & 20 & 188.6 & $55819 / 1260$ & Kipple (2004b) \\
\hline Median & & 188.4 & & \\
\hline \multicolumn{5}{|l|}{ Tour vessels } \\
\hline 'Sea Lion' & 10.9 & 178.5 & $99 / 62$ & Kipple \& Gabriele (2004) \\
\hline 'Spirit of Alaska' & 10.5 & 179.8 & $97 / 78$ & Kipple \& Gabriele (2004) \\
\hline 'Baranof Wind' & $\sim 20$ & 177.5 & $77 / 149$ & This study \\
\hline
\end{tabular}




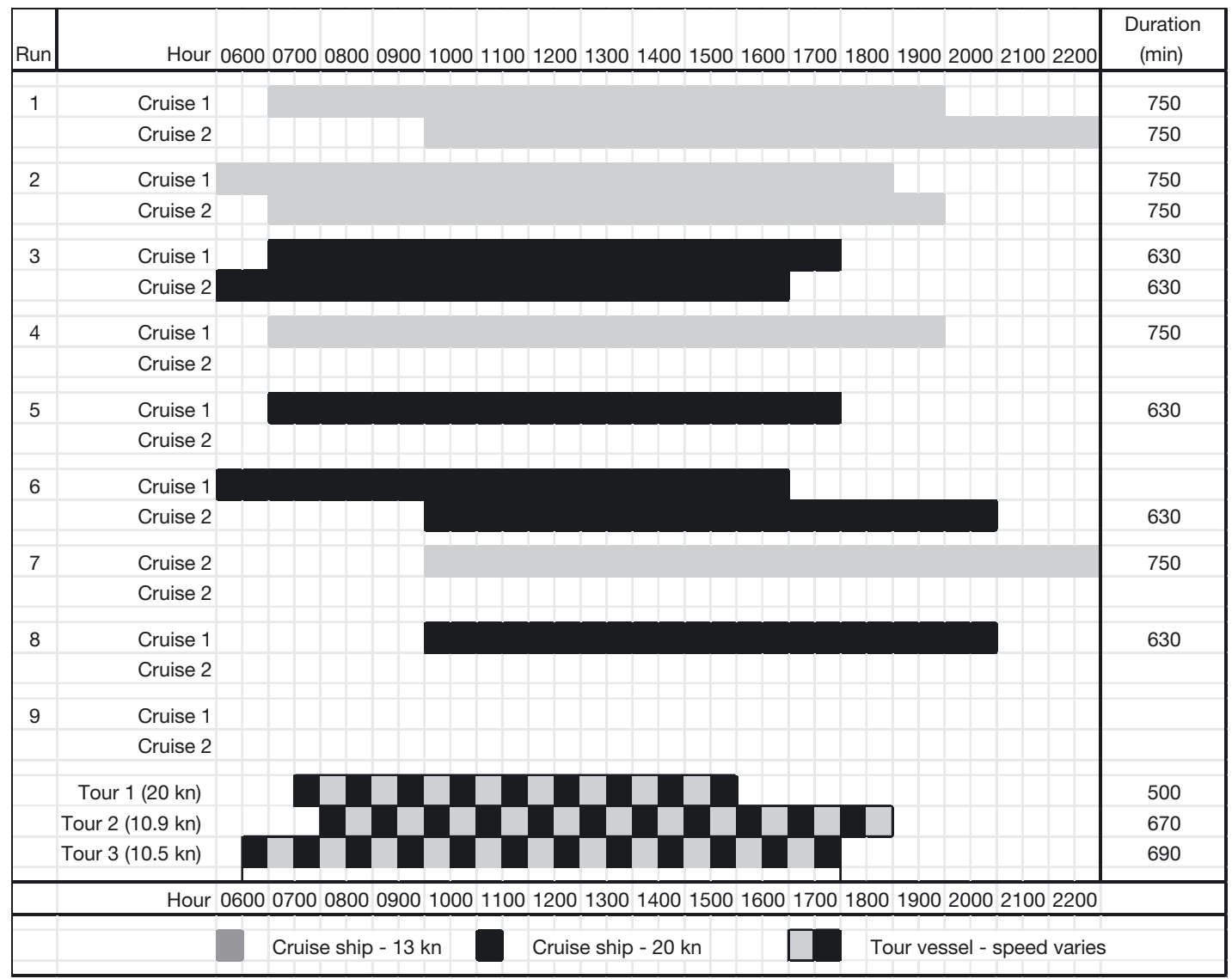

Fig. 7. Schematic drawing of the start and end times for vessels in each simulation. Runs 1 to 8 list the number and timing of cruise ships. The $13 \mathrm{knot}(\mathrm{kn})$ cruise ships are shown in black and $20 \mathrm{kn}$ cruise ships are shown in un-bordered grey. The tour vessels, whose speeds ranged from 10 to $20 \mathrm{kn}$, are shown in checkered grey and black. Tour vessels are present in runs 1-9, but they are omitted in any run with an 'NT' suffix

modeled were mid-sized vessels (30 to $60 \mathrm{~m}$ ) and 69 to 100 gross t. Since 1999, GBNP has worked with acousticians at the US Naval Surface Warfare Center to make calibrated measurements of the frequency spectra of a variety of small craft and large vessels and to characterize ambient noise in Glacier Bay (Kipple 2002, 2004a,b). These measurements were used in the AIM modeling effort.

\section{Cruise ships}

Cruise ship acoustic characteristics were derived from calibrated measurements of 4 ships traveling at approximately 10 to $20 \mathrm{kn}$ with frequencies from 10 to $4000 \mathrm{~Hz}$ or greater (Kipple 2002, 2004a,b). These 4 ships were typical of ships visiting Glacier Bay and were chosen because their calibrated runs were made at or near the speeds of interest, 13 and $20 \mathrm{kn}$ (Table 2). Broadband (e.g. 10 to $4000 \mathrm{~Hz}$ ) sound levels of the ships were 2.4 to $20.1 \mathrm{~dB}$ re $1 \mu \mathrm{Pa}$ (mean
$7.7 \mathrm{~dB}$ re $1 \mu \mathrm{Pa}$ ) louder at $\sim 20 \mathrm{kn}$ than they were at $\sim 10 \mathrm{kn}$ (Table 2). Each type of cruise ship animat (i.e. 13 and $20 \mathrm{kn}$ ) used a median value of all 4 broadband source level values (179.1 and $188.4 \mathrm{~dB}$ re $1 \mu \mathrm{Pa}$ at $1 \mathrm{~m})$. The measured values at $\sim 10 \mathrm{kn}$ were not adjusted for the $13 \mathrm{kn}$ ship simulations. This was done largely because the observed difference in median source levels $(\sim 9.3 \mathrm{~dB})$ was less than expected based on the prediction of the Ross speed-dependence model (9.9 dB; Ross 1976, their Fig. 8.21). The Ross model still applies well when referring to a specific ship (Heitmeyer et al. 2003).

\section{Tour vessels}

A single set of 3 tour vessels was used for modeling. The model used the acoustic characteristics of 2 tour vessels that were traveling at 10.5 and $10.9 \mathrm{kn}$ derived from calibrated measurements (Kipple \& Gabriele 2004). These slower tour vessels tend to 
Table 3. Summary of descriptive measures for broadband sound levels as well as quiet and noisy times in Glacier Bay National Park. Amplitude values are reported as medians; the accompanying variation metric is the median absolute deviation (MAD). Temporal metrics are reports as means and standard deviations. MSPL: maximal sound pressure level; CSEL: cumulative sound exposure level; n/a: not applicable; NT: no tour vessels included in the run

\begin{tabular}{|c|c|c|c|c|c|c|c|c|}
\hline \multirow{3}{*}{ Simulation } & \multirow{3}{*}{$\begin{array}{l}\text { No. of } \\
\text { cruise } \\
\text { ships }\end{array}$} & \multirow{3}{*}{$\begin{array}{l}\text { Ship arrival } \\
\text { time } \\
\text { separation } \\
\text { (h) }\end{array}$} & \multicolumn{4}{|c|}{ Amplitude } & \multicolumn{2}{|c|}{ Temporal duration (min) } \\
\hline & & & \multicolumn{2}{|c|}{$-\mathrm{dB}$ re $\mu \mathrm{Pa}$} & \multicolumn{2}{|c|}{$\mathrm{dB}$ re $1 \mu \mathrm{Pa}^{2}-\mathrm{s}-$} & \multirow{2}{*}{$\begin{array}{c}\text { Noise } \\
\text { period } \\
\text { mean (SD) }\end{array}$} & \multirow{2}{*}{$\begin{array}{c}\text { Quiet } \\
\text { period } \\
\text { mean (SD) }\end{array}$} \\
\hline & & & $\begin{array}{l}\text { MSPL } \\
\text { median } \\
(\text { MAD) }\end{array}$ & $\begin{array}{l}\text { MSPL 5th-95th } \\
\text { percentile } \\
\text { range }\end{array}$ & $\begin{array}{c}\text { CSEL } \\
\text { median } \\
(\mathrm{MAD})\end{array}$ & $\begin{array}{l}\text { CSEL 5th-95th } \\
\text { percentile } \\
\text { range }\end{array}$ & & \\
\hline Run 1 & 2 slow & 3 & $128(6.8)$ & $110-144$ & $159(2.1)$ & $152-164$ & $282(117)$ & $374(307)$ \\
\hline Run 1NT & 2 slow & 3 & $122(6.5)$ & $108-141$ & $156(2.1)$ & $150-156$ & $128(61)$ & $543(303)$ \\
\hline Run 2 & 2 slow & 1 & $127(7.4)$ & $110-144$ & $159(2.3)$ & $151-164$ & $264(107)$ & $381(311)$ \\
\hline Run 2NT & 2 slow & 1 & $116(6.1)$ & $106-135$ & $152(2.8)$ & $145-152$ & $74(60)$ & 645 (315) \\
\hline Run 3 & 2 fast & 1 & $133(6.8)$ & $117-150$ & $164(2.3)$ & $157-164$ & $412(73)$ & $201(244)$ \\
\hline Run 3NT & 2 fast & 1 & $126(6.0)$ & $116-144$ & $161(2.6)$ & $155-167$ & 308 (91) & 335 (290) \\
\hline Run 4 & 1 slow & $\mathrm{n} / \mathrm{a}$ & $126(6.8)$ & $110-142$ & $158(2.1)$ & $151-163$ & $222(64)$ & 416 (311) \\
\hline Run 4NT & 1 slow & $\mathrm{n} / \mathrm{a}$ & $119(5.6)$ & $108-136$ & $153(2.1)$ & $147-153$ & (33) & $624(294)$ \\
\hline Run 5 & 1 fast & $\mathrm{n} / \mathrm{a}$ & 131 (6.5) & $117-148$ & $162(2.2)$ & $155-168$ & 331 (79) & 264 (251) \\
\hline Run 6 & 2 fast & 4 & $133(6.6)$ & $117-151$ & $164(2.0)$ & $158-170$ & $557(107)$ & $185(244)$ \\
\hline Run 6NT & 2 fast & 4 & $132(6.4)$ & $118-148$ & $164(2.1)$ & $158-169$ & 444 (96) & 214 (235) \\
\hline Run 7 & 1 slow & $\mathrm{n} / \mathrm{a}$ & $126(6.8)$ & $110-142$ & $158(2.0)$ & $151-163$ & 235 (106) & 421 (311) \\
\hline Run 8 & 1 fast & $\mathrm{n} / \mathrm{a}$ & $131(6.1)$ & $117-147$ & $162(2.1)$ & $156-167$ & $387(96)$ & $268(256)$ \\
\hline Run 9 & 0 & $\mathrm{n} / \mathrm{a}$ & $124(7.1)$ & $110-142$ & $157(2.2)$ & $151-162$ & $177(81)$ & 477 (311) \\
\hline
\end{tabular}

cruise at or near their top cruising speed as they transit Glacier Bay, thus their speed was not varied in the model. Their broadband source levels are shown in Table 2. Measurements were not available for the daily tour vessel ('Baranof Wind') operating in GBNP, but it was important to include it in the model because this is a consistent acoustic source in Glacier Bay. We estimated its source level using an opportunistic recording from the GBNP monitoring hydrophone (Kipple \& Gabriele 2003a). Analysis of the recording produced a broadband RMS received level of $121 \mathrm{~dB}$ re $1 \mu \mathrm{Pa}$ for the vessel at approximately $20 \mathrm{kn}$ and an estimated range of $1259 \mathrm{~m}$. The modeled transmission loss was $56.5 \mathrm{~dB}$, producing an estimated broadband RMS source level of $177.5 \mathrm{~dB}$ re $1 \mu \mathrm{Pa}$ at $1 \mathrm{~m}$ (see Table 2). This value corresponds well with what would be expected for a vessel of its size and type (Kipple \& Gabriele 2004). Tour vessel animats in the model used these speeds and their corresponding source levels.

\section{RESULTS}

For each animat in each simulation, AIM returned an exposure history consisting of the predicted received SPL for each whale animat for each time step. These exposure histories were analyzed to obtain the amplitude (MSPL and CSEL) and temporal (SET and QT) metrics defined in the 'Methods' section.
Across all simulations, the 95th percentile MSPLs ranged from 136 to $151 \mathrm{~dB}$ re $1 \mu \mathrm{Pa}$ (Table 3). The 5th percentile MSPLs ranged from 106 to $118 \mathrm{~dB}$ re $1 \mu \mathrm{Pa}$. Fifth percentile CSEL values ranged from 145 to $158 \mathrm{~dB}$ re $1 \mathrm{\mu Pa}^{2}$-s CSEL whereas 95th percentile CSELs ranged from 158 to $170 \mathrm{~dB}$ re $1 \mu \mathrm{Pa}^{2}$-s. The maximal MSPL and CSEL values always occurred in simulations with fast cruise ships. Conversely, the lowest MSPL and CSEL values were associated with slow cruise ship simulations.

Cumulative probability distributions of the MSPL and CSEL results (see Fig. 8), illustrate the sound exposure data with respect to the number, speed, and timing of cruise ships. Comparing MSPL values (Fig. 8a), $80 \%$ of the whale animats in the slow cruise ship simulations (runs 1, 2, 4, and 7) were exposed to MSPL levels from 134 to $136 \mathrm{~dB}$, compared to 138 to $142 \mathrm{~dB}$ for the fast cruise ship simulations (runs 3,5, 6 , and 8), a difference of 2 to $8 \mathrm{~dB}$. For both MSPL and CSEL, the 8 simulations fell into 4 tight groups. These 4 groups, from quietest to loudest (i.e. left to right), contained 1 slow cruise ship (runs 4 and 7), 2 slow cruise ships (runs 1 and 2), 1 fast cruise ship (runs 5 and 8) and 2 fast cruise ships (runs 3 and 6). The cumulative CSEL distributions (Fig. 8b) show the clearest delineation between the simulations because integrating the acoustic energy across the entire day provides a more robust metric than relying on the single loudest MSPL per whale animat. The fast ship simulations had shorter sound exposure times (222 to $264 \mathrm{~min}$ ) than the slow ship simulations (331 to $557 \mathrm{~min}$ ). 

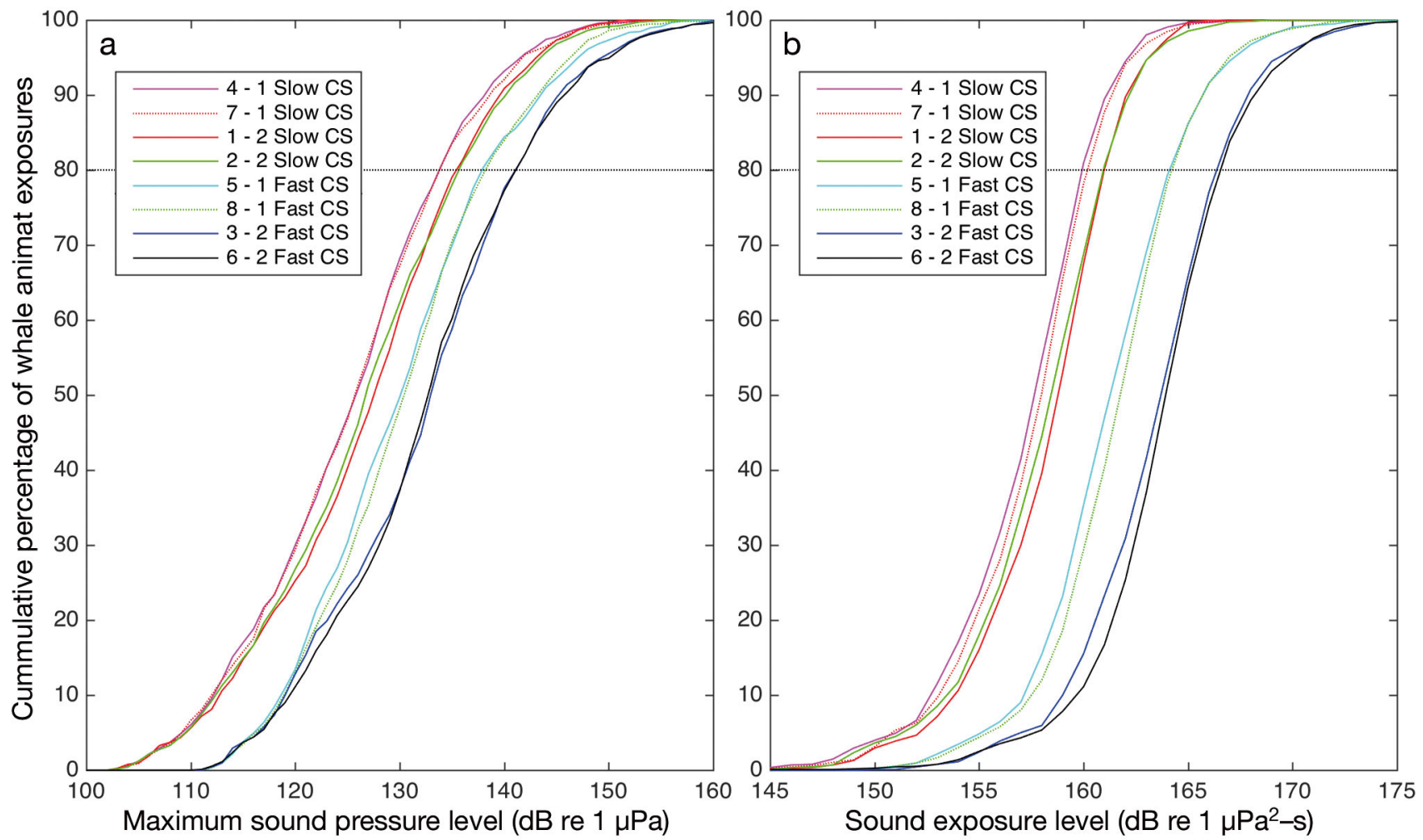

Fig. 8. Cumulative probability functions of (a) maximum sound pressure level (MSPL) and (b) cumulative sound exposure level (CSEL) for whale animat sound exposures grouped by cruise ship speed, timing, and numbers. Line styles group similar runs as follows: simulations 4 and 7 each contained 1 slow cruise ship (CS); 1 and 2 each contained 2 slow cruise ships; 5 and 8 each contained one fast cruise ship; 3 and 6 each contained 2 fast cruise ships

Table 4. Amplitude metric statistical analysis (runs 1 to 8 ). The value of the predictor parameter indicates the direction and magnitude of the effect. MSPL: maximal sound pressure level; CSEL: cumulative sound exposure level

\begin{tabular}{|c|c|c|c|c|c|c|c|c|}
\hline & \multicolumn{4}{|c|}{$\longrightarrow$ MSPL (per animat) } & \multicolumn{4}{|c|}{$\longrightarrow$ CSEL (per animat) } \\
\hline & $\begin{array}{c}\text { Predictor } \\
\text { parameter estimate }\end{array}$ & $\mathrm{SE}$ & $t$-ratio & Prob $>t$ & $\begin{array}{c}\text { Predictor } \\
\text { parameter estimate }\end{array}$ & $\mathrm{SE}$ & $t$-ratio & Prob $>t$ \\
\hline Intercept & 124.6 & 0.454 & 274.0 & $\mathrm{p}<0.001$ & 157.0 & 0.164 & 953.9 & $\mathrm{p}<0.001$ \\
\hline No. of ships & 1.322 & 0.287 & 4.6 & $\mathrm{p}<0.001$ & 0.0832 & 0.104 & 8.0 & $\mathrm{p}<0.001$ \\
\hline Ship speed & 5.532 & 0.203 & 27.2 & $\mathrm{p}<0.001$ & 4.823 & 0.073 & 65.5 & $\mathrm{p}<0.001$ \\
\hline Speed $\times$ no. of ships & 0.894 & 0.406 & 2.2 & $\mathrm{p}<0.001$ & 1.395 & 0.147 & 9.5 & $\mathrm{p}<0.001$ \\
\hline
\end{tabular}

The amplitude and temporal metrics were analyzed using the combined output of runs 1 to 8 . The first analysis used the number and speed of cruise ships as predictor variables, as well as an interaction term. The results of both amplitude analyses were statistically significant (MSPL: $F_{3,9280}=273.5, \mathrm{p}<$ 0.001; CSEL: $F_{3,9280}=1603.5, \mathrm{p}<0.001$; Table 4). The $\mathrm{r}^{2}$ value of the MSPL analysis was 0.081, while CSEL analysis value was 0.341 . This indicates that the daily integrated CSEL metric explained more of the variability between whale animats than the instantaneous MSPL metric. This was not surprising since the MSPL is a measure of the single loudest moment of an animat's time history, whereas the CSEL integrates the total acoustic exposure across an entire day.

Pairwise comparisons of using least-square means contrast found that 2 cruise ships produced significantly higher MSPL values $\left(F_{1,9276}=21.31, \mathrm{p}<\right.$ $0.0001)$ and CSEL values $\left(F_{1,9276}=26.05, \mathrm{p}<\right.$ $0.0001)$. Likewise, when comparing the same number of fast and slow cruise ships, model simulations showed that faster cruise ships produced significantly higher MSPL $\left(F_{1,9276}=312.60, \mathrm{p}<0.0001\right)$ and CSEL $\left(F_{1,9276}=90.98, \mathrm{p}<0.0001\right)$ values than slower ships. 
Table 5. Temporal metric pairwise comparison results

\begin{tabular}{|c|c|c|c|c|c|c|c|c|}
\hline & \multicolumn{4}{|c|}{ - Quiet time (per animat) - } & \multicolumn{4}{|c|}{ Cumulative sound exposure time (per animat) } \\
\hline & $\begin{array}{c}\text { Predictor } \\
\text { parameter estimate }\end{array}$ & $\mathrm{SE}$ & $t$-ratio & Prob $>t$ & $\begin{array}{c}\text { Predictor } \\
\text { parameter estimate }\end{array}$ & SE & $t$-ratio & Prob $>t$ \\
\hline Intercept & 697.2 & 24.9 & 27.9 & $\mathrm{p}<0.001$ & 738.9 & 19.6 & 37.7 & $\mathrm{p}<0.001$ \\
\hline No. of ships & -80.7 & 15.8 & -5.1 & $\mathrm{p}<0.001$ & 176.8 & 12.4 & 14.3 & $\mathrm{p}<0.001$ \\
\hline Ship speed & -155.7 & 11.2 & -13.4 & $\mathrm{p}<0.001$ & 683.8 & 8.9 & 78.09 & $\mathrm{p}<0.001$ \\
\hline Speed $\times$ no. of ships & -9.9 & 22.3 & -0.44 & $\mathrm{p}=0.65$ & 327.1 & 17.5 & 18.7 & $\mathrm{p}<0.001$ \\
\hline
\end{tabular}

Tests of both temporal variables were also statistically significant (QT: $F_{3,9276}=84.5, \mathrm{p}<0.001$; SET: $F_{3,9276}=2652.2, \mathrm{p}<0.001 ;$ Table 5). The $\mathrm{r}^{2}$ value of the 2 analyses differed markedly, with QT having a value of 0.026 and SET had a value of 0.461 (Table 5). Both analyses indicated that both faster and greater number of ships decreased QT and increased SET. SET had a much higher $\mathrm{r}^{2}$ value and a significant interaction term. The least square means for the interaction term, shown in Table 6, illustrate the effect of these 2 variables. The differences were significant at $\alpha=0.05$. These values clearly show that increases in the number and speed of vessels lead to increases in the amount of time that whales are exposed to noise in excess of $110 \mathrm{~dB}$.

\section{Timing of ship arrivals at Glacier Bay}

Changing the arrival time of the vessels without changing any other factors had a minimal effect on the sound received level metrics (Table 3). However, amplitude is only one component of the acoustic environment. Temporal distribution of noise is another. Since the animals are constantly moving, the hypothesis is that if cruise ship transits are clumped temporally, animals near one vessel will likely hear both vessels, while those animals far enough away will be 'missed' by both vessels. Similarly, whales that are near both of the day's ships during a single noise event may experience longer noise-free periods during the rest of the day.

To focus on this issue, we compared model output from the 2 cruise ships runs without tour vessels (runs 1NT, 2NT, 3NT and 6NT) that differ only by cruise ship timing. The cumulative distribution of sound exposure times for those 4 runs is shown in Fig. 9 and the mean CSET values are shown in Table 7. The longest sound exposure times were generated in the simulation with 2 fast cruise ships with a $4 \mathrm{~h}$ arrival interval. The shortest times were found in the simulation with 2 slow vessels arriving
Table 6. Cumulative sound exposure time (CSET) least square means for speed and number of ships

\begin{tabular}{|lccc|}
\hline $\begin{array}{l}\text { Speed } \\
(\mathrm{kn})\end{array}$ & $\begin{array}{c}\text { No. of } \\
\text { cruise ships }\end{array}$ & $\begin{array}{c}\text { CSET least } \\
\text { square mean (s) }\end{array}$ & SE \\
\hline 13 & 1 & 916 & 8.76 \\
13 & 2 & 1093 & 8.76 \\
20 & 1 & 1436 & 8.76 \\
20 & 2 & 1940 & 8.76 \\
\hline
\end{tabular}

Table 7. Cumulative sound exposure time (CSET) least square means for cruise ship speed and arrival time interval

\begin{tabular}{|lccc|}
\hline $\begin{array}{l}\text { Speed } \\
(\mathrm{kn})\end{array}$ & $\begin{array}{c}\text { Cruise ship } \\
\text { time interval }\end{array}$ & $\begin{array}{c}\text { CSET least square } \\
\text { mean (min) }\end{array}$ & SE \\
\hline 13 & Short & 298 & 9.16 \\
13 & Long & 511 & 9.14 \\
20 & Short & 1235 & 9.15 \\
20 & Long & 1776 & 9.14 \\
\hline
\end{tabular}

$1 \mathrm{~h}$ apart. The 2 intermediate cases (fast and short interval, slow and long interval) had very similar results. For both speed classes, the $1 \mathrm{~h}$ interval between arrival times produced shorter noisy periods than the longer time interval. A GLM test confirmed that differences were statistically significant $\left(F_{3,4628}\right.$ $=5501.5, \mathrm{p}<0.0001)$.

\section{Presence of tour vessels}

To examine the contributions of tour vessels to underwater noise in Glacier Bay, we compared model output from simulations without cruise ships (run 9) with those containing various numbers of cruise ships traveling at slow and fast speeds. The quietest simulation (run 4, with 1 slow cruise ship) and the loudest (run 6, with 2 fast cruise ships) were re-run without tour vessels to assess the impact of tour vessels relative to cruise ships (Fig. 10). Removing tour vessels from simulation 4 produced a 6 to 


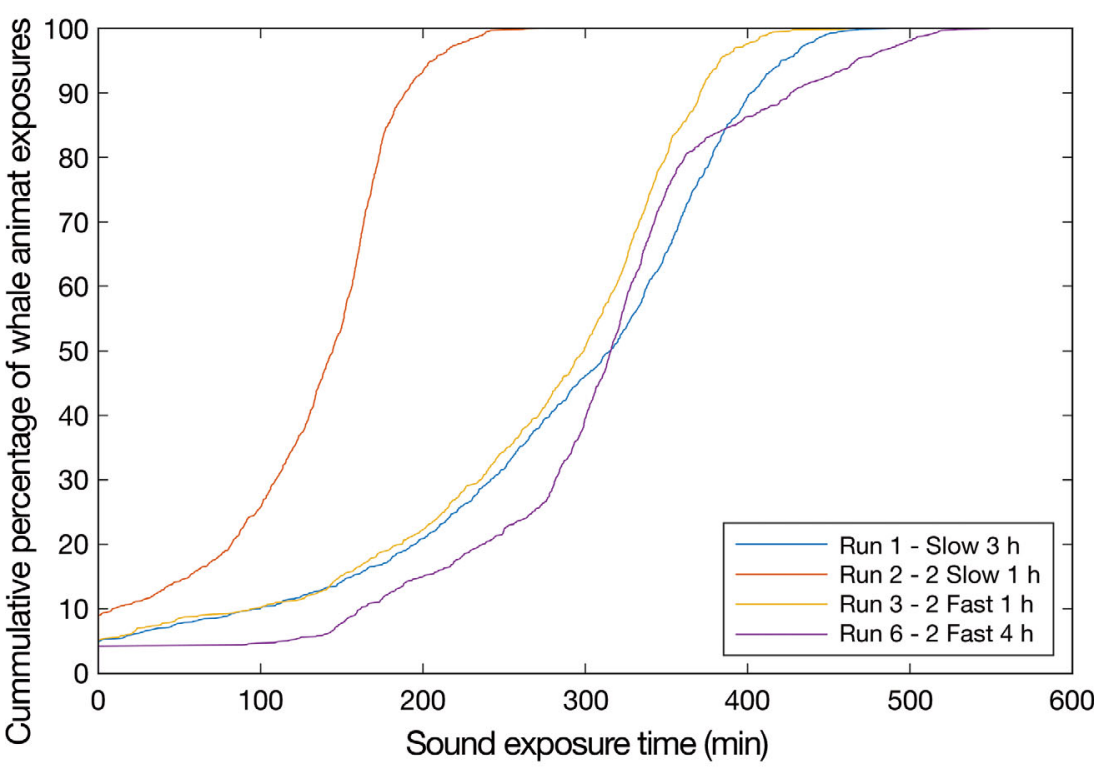

Fig. 9. Cumulative percentage of sound exposure time for the 4 cruise ship-only runs. Differences in the distributions are readily seen. Two fast ships with a $4 \mathrm{~h}$ difference in arrival times produced the longest sound exposure times. The next 2 were 2 slow cruise ships with a $3 \mathrm{~h}$ arrival time difference and 2 fast ships with a $1 \mathrm{~h}$ interval. The lowest duration exposures were produced by 2 slow ships with a $1 \mathrm{~h}$ arrival time difference

$7 \mathrm{~dB}$ decrease, compared to $<1 \mathrm{~dB}$ for simulation 6 . These differences were statistically significant for both MSPL $\left(F_{3,4636}=510.8, \mathrm{p}<0.0001\right)$ and CSEL $\left(F_{3,4636}=2873.6, \mathrm{p}<0.0001\right)$. Comparing the simulation with no cruise ships (run 9) to simulation 4NT revealed that the combined CSEL of the 3 tour vessels is greater than that of a single slow cruise ship but less than 2 fast cruise ships (Fig. 10).

\section{Theoretical effect of speed reduction on MSPL and CSEL metrics}

The cruise ships used in the model (Table 2) were on average $9 \mathrm{~dB}$ quieter at slower speeds than higher speeds, but not all ships are substantially quieter at lower speeds (Kipple 2002, Trevorrow et al. 2008). Therefore, we estimated how CSEL values would change in cases where ship source levels were not sharply dependent on ship speed and, for example, where ships were only a few $\mathrm{dB}$ quieter at the slower speed.

We considered the case of 2 hypothetical ships with identical acoustic characteristics passing by a whale at different speeds. To do so, we calculated the difference in sound exposure duration necessary to produce equivalent CSEL values from ships with different source levels using the following equation (the reference pressure level of $1 \mu \mathrm{Pa}$ has been omitted for clarity):

$$
\mathrm{CSEL}_{1}=\mathrm{CSEL}_{2}
$$

$10 \times \log _{10}\left(\right.$ Sound Pressure $\left.{ }_{1}^{2}\right) \times t_{1}=$ $10 \times \log _{10}\left(\right.$ Sound Pressure $\left.2{ }_{2}^{2}\right) \times t_{2}$

which reduces to:

$$
\begin{gathered}
t_{1}=\underset{\text { Sound Pressure }}{1}{ }^{2} \\
\quad \exp \left(\text { Sound }_{2}\right) \times t_{2} /
\end{gathered}
$$

where $t=$ time of exposure and $\mathrm{SL}=$ source level of the vessel. The relationship between the difference in source level and the amount of time needed to produce the same CSEL is shown in Fig. 11.

In this study (Table 2), $\mathrm{SL}_{1}=179$ (at $13 \mathrm{kn}$ ) and $\mathrm{SL}_{2}=188$ (at $20 \mathrm{kn}$ ), which represents a $9 \mathrm{~dB}$ difference between Sound Pressure 1 and 2 . Therefore the slower vessel would have required an exposure duration of 7.5 times longer than the faster vessel to achieve an equivalent CSEL. In the real world, the pass-by duration of a vessel traveling at $13 \mathrm{kn}$ will be approximately 1.5 times as long as the pass-by duration of a vessel traveling at $20 \mathrm{kn}$. Because the difference in pass-by duration is unlikely to be different enough to compensate for the increased CSEL, for vessels whose radiated noise increases in source level with increasing speed, slower vessels will probably always produce lower MSPL and CSEL metrics, even when $\mathrm{SL}_{1}$ and $\mathrm{SL}_{2}$ are separated by only a few $\mathrm{dB}$.

\section{DISCUSSION}

The AIM was used to examine how cruise ship speed, numbers, and timing affect the sound exposure of humpback whales in Glacier Bay. CSEL was found to be a more robust metric than the MSPL for these purposes. We showed for the first time that, under plausible operating conditions within this region, a faster, louder vessel results in a higher CSEL than a slower, quieter vessel, and that this finding should hold true even if the slower vessel is only a few decibels quieter (i.e. 1 or $2 \mathrm{~dB}$ ) than the faster vessel. While synchronizing the ship arrival times had little effect on whale acoustic exposure metrics (Table 3), it resulted in appreciable decreases in the 


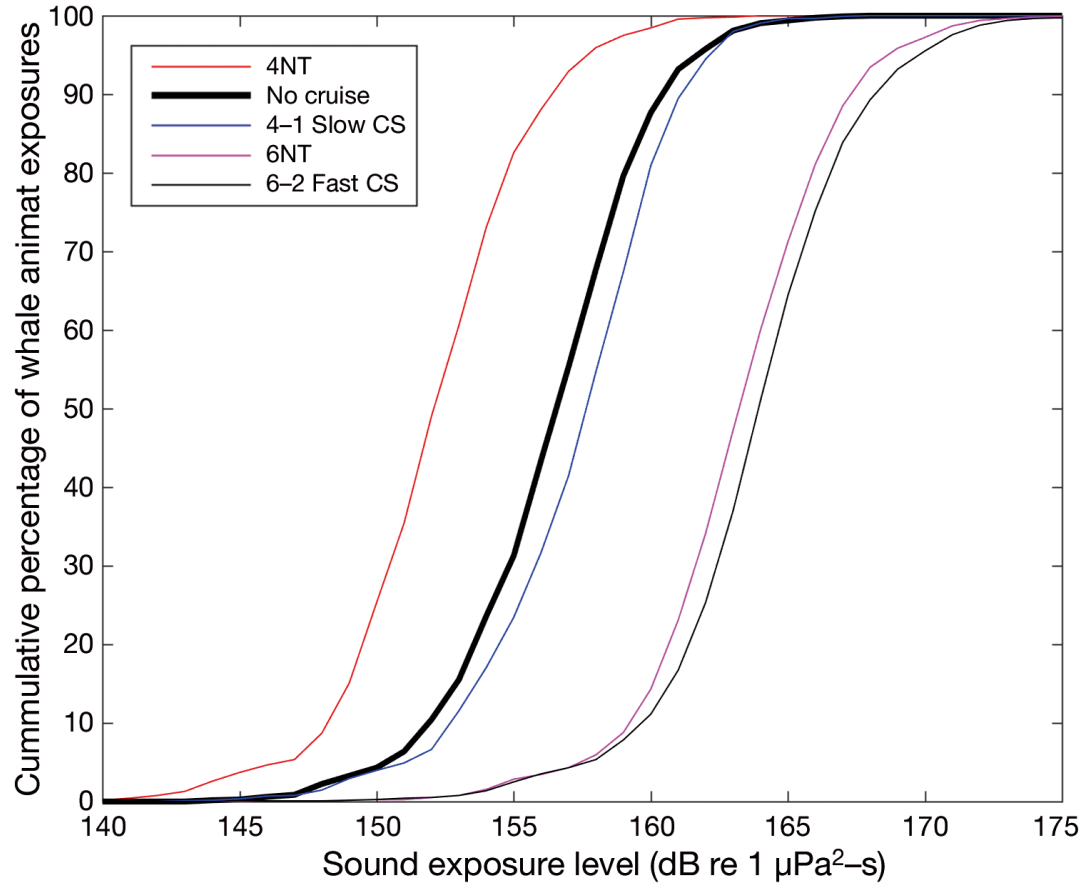

Fig. 10. Cumulative probability distribution of cumulative sound energy level (CSEL) comparing the simulations with and without (NT) tour vessels. Removing tour vessels from run 4 produced an approximate $6 \mathrm{~dB}$ decrease in CSEL, compared to a $<1 \mathrm{~dB}$ drop when tour vessels were removed from run 6 . CS: cruise ship

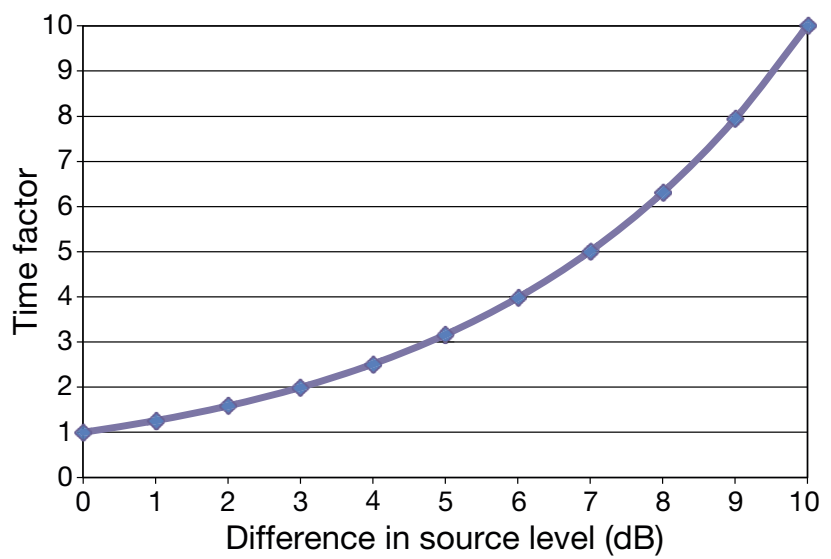

Fig. 11. Relationship between differences in source level and amount of time needed to generate an equivalent cumulative sound energy level (CSEL). For example, decreasing a vessel's source level by $3 \mathrm{~dB}$ means that to produce the same CSEL value, it would have to be in the area for twice as long

CSET metric (Table 3, Fig. 9). This work provides a cost-effective way to quantitatively assess real-world management questions about vessel operations specific to GBNP while revealing generalities that are applicable to other types of vessels and circumstances. Acoustic habitat characteristics are extremely important to understand in areas inhabited by baleen whales and likely confer benefits to other sensitive but lessstudied marine species.

\section{Number of vessels}

The trend is clear and unsurprising that fewer ships operating in Glacier Bay translates into lower acoustic exposure. The decrease in acoustic exposure (Tables 3, 4 \& 5) from reducing daily cruise ship visits from 2 to 1 was small compared to reducing ship speed from about 20 to $13 \mathrm{kn}$. The effect of adding a second ship was greatly reduced by having the ships travel at a slower speeds, as illustrated by the lower median values of MSPL and CSEL for simulations with 2 slow cruise ships compared to those with a single fast cruise ship (Table 3).

The temporal metrics also showed that QT increased and CSET decreased when a single ship was present. Similar to amplitude metrics, the CSET showed smaller values with 2 slow cruise ships than with a single fast cruise ship. The sound exposure metrics used here, the behavioral and perceptual effects of a single versus multiple vessel transits, must also be considered as discussed below.

\section{Ship speed}

Cruise ship speed was the dominant factor affecting whale noise exposure in Glacier Bay, as has been reported elsewhere (Houghton et al. 2015). The statistical model results demonstrated that greater ship speed explained most of the variation in the increased MSPL, CSEL and CSET metrics. The higher MSPL was expected since the faster ships were also louder. However, CSEL increased as well, despite faster ships transiting an area more quickly, reducing exposure duration. Perhaps the importance of ship speed is best illustrated by the finding that the median exposure values for simulations with 2 slow cruise ships were lower than those with a single fast cruise ship.

Prior to this study it was not known whether longer exposure times by ships traveling at slower speeds would produce higher or lower integrated daily noise exposures (i.e. CSEL) than faster ships. This study 
found that cruise ships traveling at $13 \mathrm{kn}$ produced CSEL levels 3 times lower than those traveling at $20 \mathrm{kn}$ and that MSPL levels also decreased. The methodology introduced here can be applied to any situation where the cumulative effects of vessel speed restrictions are being considered.

As most vessels' source levels increase with speed, slower vessels will almost always produce lower MSPL and CSEL metrics, even when differences in source levels are not substantial. Our results may therefore be applied beyond the speeds and vessels modeled here, although continued efforts to measure ship source levels at different speeds will be needed to ensure that modeling efforts use contemporary vessel noise characteristics.

\section{Timing of cruise ship arrivals}

Regardless of ship speed, small amplitude differences (Table 3, Fig. 8) were found between simulations where 2 ships arrived an hour apart versus ship arrivals separated by 3 or $4 \mathrm{~h}$. Arrivals in close temporal proximity (i.e. $1 \mathrm{~h}$ ) consistently resulted in slightly higher MSPL values (2 to $5 \mathrm{~dB}$ ) and CSEL ( 1 dB) than ships arriving 3 or $4 \mathrm{~h}$ apart (Fig. 8). These small, nonsignificant differences may be due to slight variations in the relative positions of animals and vessels during simulations.

However, the temporal metrics (Table 5) showed a remarkable change when the timing was altered. Increases in both the number and speed of cruise ships produced increases in the SET metric and decreases in the QT metric. The cumulative percentage of sound exposure times for different arrival intervals (Fig. 9) was clear: Scheduling vessels with smaller time intervals reduced sound exposure times.

Scheduling ship transits close in time appears to create quiet periods that may have benefits to whale communication or behavior (Clark et al. 2009) that would not be represented by the total CSEL metric. However, other vessel traffic (including tour vessels and small vessels) has the potential to create noise during any planned quiet period based solely on cruise ship scheduling adjustments, potentially reducing the benefit of synchronizing cruise ship scheduling.

\section{Presence of tour vessels}

Statistically significant differences in MSPL and CSEL indicate that on days that are relatively quiet (i.e. run 4 with 1 slow cruise ship), tour vessel noise dominates the GBNP underwater acoustic environment. But on relatively noisy days (i.e. run 6 with 2 fast cruise ships) cruise ship noise was the dominant contributor to the Bay's soundscape. For example, the difference in median CSEL for run 4 versus $4 \mathrm{NT}$ was $5 \mathrm{~dB}$, whereas there was no difference in median CSEL for run 6 versus 6NT. Thus, the acoustic contribution of tour vessels becomes more important in GBNP as the number and speed of cruise ships declines.

\section{Biological and behavioral implications of sound exposure}

Loud sound can impair hearing function and cause physical damage to ear structures resulting in temporary or permanent hearing loss (i.e. a temporary threshold shift [TTS] or PTS in hearing sensitivity at different frequencies). None of the AIM-simulated whale animats received vessel noise at levels believed to be loud enough to cause TTS (i.e. unweighted CSEL of $\sim 180 \mathrm{~dB}$ ) according to the latest proposed acoustic guidance (NOAA 2016). Since physiological responses are very unlikely, this study focused on sound exposure relevant to potential behavioral responses.

Sounds that do not exceed TTS or PTS thresholds can still cause behavioral effects and mask whale communication. The analyses presented here, based upon estimates of MSPL or CSEL, are useful metrics for assessing both biological effects of noise and the potential value of specific vessel management actions. However, as yet, there is no clear way to predict the effects of different MSPL or CSEL on whale behavior. First, there is great and persistent uncertainty in our understanding of the relationship between sound and behavior (Clark \& Ellison 2004). Second, whales are long-lived, social animals whose behavioral context, social ties, and previous experiences with vessels and other noise sources may strongly affect their response under a given set of circumstances (Bejder et al. 2006, Ellison et al. 2012).

A recent review of behavioral responses to noise found no evidence for a direct correlation between whale behavior and increasing levels of MSPL or CSEL, especially at sound levels below $120 \mathrm{~dB}$ (Southall et al. 2007). Nevertheless, it is reasonable to assume that the probability of behavioral reactions by whales to noise increases as noise levels increase from 120 to $160 \mathrm{~dB}$ re $1 \mu \mathrm{Pa}$ when all other environmental and behavioral parameters are constant (Southall et al. 2007). Under the Marine Mammal 
Protection Act, NMFS requires ocean users to obtain permits for certain human activities that could expose baleen whales to non-continuous sound levels greater than $160 \mathrm{~dB}$ re $1 \mu \mathrm{Pa}$ or continuous sound levels greater than $120 \mathrm{~dB}$ re $1 \mu \mathrm{Pa}$ (Scholik-Schlomer et al. 2009). Although these guidelines have not been applied to vessel propulsion noise, the sound exposure levels estimated for AIM runs fell well within this range. Therefore, the potential for behavioral responses or masking of whale communications would be greater at higher MSPL and CSEL values.

Behavioral effects may be particularly problematic in the assessment of the effect of different numbers of ships. For example, it is not unreasonable to surmise that multiple noise events (i.e. recurring or simultaneous vessel pass-bys) could have a non-linear effect on a whale's behavior through the processes of sensitization, tolerance, and/or habituation to vessel noise that is neither constant nor directly related to given MSPL or CSEL values. Sensitization describes an increase in responsiveness caused by previous vessel pass-bys, while habituation describes a reduction in response after the first vessel pass-by.

Nonetheless, the results of this study suggest that humpback whales and other marine mammals in Glacier Bay are subject to the temporary loss of acoustic habitat as a result of acoustic masking by large vessel traffic, whose noise spectra overlaps that of whale vocalizations. This temporary loss may impede their ability to communicate (after Clark et al. 2009). Quantifying the biological effects of acoustic masking on whales is beyond the scope of this study, but the potential effects can be qualitatively described. In Glacier Bay during spring and summer, humpback whales use a variety of vocalizations (Fournet et al. 2015) to contact and socialize with one another while feeding and calf rearing. The predominant vocalizations are short, simple 'whup' calls, likely contact calls (Wild \& Gabriele 2014) that could be rendered inaudible by vessel noise in a way similar to those documented for right whale calls (Clark et al. 2009, Tennessen \& Parks 2016). On the humpback whale's tropical wintering grounds, male humpback whales spend copious amounts of time on song displays integral to their mating system (Frankel et al. 1995, Darling et al. 2006, Herman 2017). Males are known to sing in late summer and fall in Glacier Bay (Gabriele \& Frankel 2002) and it is speculated that high-latitude song on or adjacent to feeding areas may also be important to the reproductive success of individual males (Charif et al. 2001, Gabriele \& Frankel 2002). There is also a persistent suspicion that at least some non-calving female humpback whales may not migrate to the winter breeding areas every year (Brown et al. 1995, Craig \& Herman 1997). Although the biological effects are difficult to predict, it would seem prudent to protect humpback whale acoustic habitat as an essential aspect of natural resource protection in the context of a National Park (Hatch \& Fristrup 2009).

\section{Management implications}

National Parks in the United States are exceptional areas set aside for resource preservation and enjoyment by the public. Striking a balance between these competing interests is a continual challenge for managers. In GBNP, the motorized vessels that bring visitors to the Park also add noise to the underwater acoustic environment, and thus have a direct impact on humpback whale habitat quality. Limiting the number and/or speed of cruise ships could decrease possible impacts but it could also decrease the number of Park visitors. Similarly, speed restrictions could decrease impacts but may be perceived as burdensome for a user group highly dependent on strict schedules at port calls outside the Park. Quantitative efforts such as the AIM analysis described here can help managers understand the probability of effects of specific management actions and help guide these difficult decisions.

Reducing the speeds of cruise ships, and/or otherwise quieting these ships offers a far greater prospect for lessening daily ship noise and related impacts on humpback whale behavior than lowering the allowable number of cruise ship entries or synchronizing the timing of their arrivals in GBNP. The decrease in acoustic exposure from reducing daily cruise ship visits from 2 to 1 was small compared to reducing ship speed from about 20 to $13 \mathrm{kn}$. The effect of adding a second ship was greatly reduced by having the ships travel at a slower speeds, as illustrated by the lower median values of MSPL and CSEL for simulations with 2 slow cruise ships compared to those with a single fast cruise ship. Available information also indicates that a benefit of reducing vessel speed is a lower probability of whale mortalities from ship strikes (Laist et al. 2001, Vanderlaan \& Taggart 2007). Most, if not all, marine protected areas with concerns about baleen whales could thus experience a twofold benefit from lower ship speeds.

A marine protected area 'should be a place that provides exceptional ecological protection for marine species' (Haren 2007, p. 162). Moreover, marine protected areas have a special responsibility and oppor- 
tunity as natural laboratories, fostering an improved understanding of resource issues such as anthropogenic noise and helping to develop creative approaches to reducing any impacts. The NPS has clear authority to regulate and manage noise (Hatch \& Fristrup 2009), and the landlocked nature of GBNP largely eliminates the infiltration of anthropogenic noise from outside its boundaries, which can hamper noise management efforts in mid-ocean marine protected areas (e.g. Hatch et al. 2008, Hatch \& Fristrup 2009). Now, with these results from the AIM, GBNP has quantitative guidance for minimizing the acoustic footprint of large vessels and can evaluate options for preserving the underwater sound environment. Moreover, the methods developed for this particular environment serve as a framework for exploring management strategies in other marine environments where vessel-generated underwater noise is a concern.

Acknowledgements. We appreciate the assistance of Kathy Vigness-Raposa with the bathymetric map. We thank Christopher Clark, Bill Ellison, Leila Hatch and Blair Kipple for helpful comments on earlier manuscript drafts. We thank Jan Straley and anonymous reviewers for many helpful comments that improved the manuscript. Funding for this study was provided by the National Park Service and the NPS Fee Demonstration Program. This is MAI Tech Note TN-17-014. Thanks to Margaret A. Barker for editorial review.

\section{LITERATURE CITED}

Arveson PT, Vendittis DJ (2000) Radiated noise characteristics of a modern cargo ship. J Acoust Soc Am 107: 118-129

Baker CS, Herman LM (1989) The behavioral responses of summering humpback whales to vessel traffic: experimental and opportunistic observations. Tech Rep NPSNR-TRS-89-01. US Department of the Interior, National Park Service, Anchorage, AK. www.nps.gov/glba/learn/ nature/upload/Baker_Herman_1989_BehavioralResponses OfHumpbackWhales.pdf

Barber JR, Crooks KR, Fristrup KM (2010) The costs of chronic noise exposure for terrestrial organisms. Trends Ecol Evol 25:180-189

Bejder L, Samuels A, Whitehead H, Gales N (2006) Interpreting short-term behavioural responses to disturbance within a longitudinal perspective. Anim Behav 72: 1149-1158

Brown MR, Corkeron PJ, Hale PT, Schultz KW, Bryden MM (1995) Evidence for a sex-segregated migration in the humpback whale (Megaptera novaeangliae). Proc Biol Sci 259:229-234

* Charif RA, Clapham PJ, Clark CW (2001) Acoustic detections of singing humpback whales in deep waters off the British Isles. Mar Mamm Sci 17:751-768

Clark CW, Ellison WT (2004) Potential use of low-frequency sounds by baleen whales for probing the environment: evidence from models and empirical measurements. In:
Thomas JA, Moss CF, Vater M (eds) Advances in the study of echolocation in bats and dolphins. University of Chicago Press, Chicago, IL, p 564-589

Clark CW, Ellison WT, Southall BL, Hatch L, Van Parijs SM, Frankel A, Ponirakis D (2009) Acoustic masking in marine ecosystems: intuitions, analysis, and implication. Mar Ecol Prog Ser 395:201-222

Craig AS, Herman LM (1997) Sex differences in site fidelity and migration of humpback whales (Megaptera novaeangliae) to the Hawaiian Islands. Can J Zool 75: 1923-1933

Dalla Rosa L, Secchi ER, Maia YG, Zerbini AN, HeideJørgensen MP (2008) Movements of satellite-monitored humpback whales on their feeding ground along the Antarctic Peninsula. Polar Biol 31:771-781

* Darling JD, Jones ME, Nicklin CP (2006) Humpback whale songs: Do they organize males during the breeding season? Behaviour 143:1051-1101

Dolphin WF (1987a) Dive behavior and estimated energy expenditure of foraging humpback whales in southeast Alaska. Can J Zool 65:354-362

* Dolphin WF (1987b) Ventilation and dive patterns of humpback whales, Megaptera novaeangliae, on their Alaskan feeding grounds. Can J Zool 65:83-90

*Dolphin WF (1988) Foraging dive patterns of humpback whales, Megaptera novaeangliae, in southeast Alaska USA: a cost-benefit analysis. Can J Zool 66:2432-2441

*Ellison WT, Southall BL, Clark CW, Frankel AS (2012) A new context-based approach to assess marine mammal behavioral responses to anthropogenic sounds. Conserv Biol 26:21-28

* Ellison WT, Racca R, Clark CW, Streever B and others (2016) Modeling the aggregated exposure and responses of bowhead whales Balaena mysticetus to multiple sources of anthropogenic underwater sound. Endang Species Res 30:95-108

Erbe C (2002) Underwater noise of whale-watching boats and potential effects on killer whales (Orcinus orca), based on an acoustic impact model. Mar Mamm Sci 18: $394-418$

Frbe C (2015) The Maskogram: a tool to illustrate zones of masking. Aquat Mamm 41:434-443

Erbe C, McCauley R, McPherson C, Gavrilov A (2013) Underwater noise from offshore oil production vessels. J Acoust Soc Am 133:EL465-470

Fournet ME, Szabo A, Mellinger DK (2015) Repertoire and classification of non-song calls in southeast Alaskan humpback whales (Megaptera novaeangliae). J Acoust Soc Am 137:1-10

Frankel AS, Clark CW, Herman LM, Gabriele CM (1995) Spatial distribution, habitat utilization, and social interactions of humpback whales, Megaptera novaeangliae, off Hawai'i, determined using acoustic and visual techniques. Can J Zool 73:1134-1146

Frankel AS, Ellison WT, Buchanan J (2002) Application of the Acoustic Integration Model (AIM) to predict and minimize environmental impacts. IEEE J Oceanic Eng 2002: 1438-1443

Friedlaender AS, Hazen EL, Goldbogen JA, Stimpert AK, Calambokidis J, Southall BL (2016) Prey-mediated behavioral responses of feeding blue whales in controlled sound exposure experiments. Ecol Appl 26:1075-1085

Gabriele CM, Frankel AS (2002) The occurrence and significance of humpback whale songs in Glacier Bay, southeastern Alaska. Arctic Res US 16:42-47 
Gabriele CM, Straley JM, Herman LM, Coleman RJ (1996) Fastest documented migration of a North Pacific humpback whale. Mar Mamm Sci 12:457-464

Goldbogen JA, Calambokidis J, Croll DA, Harvey JT and others (2008) Foraging behavior of humpback whales: kinematic and respiratory patterns suggest a high cost for a lunge. J Exp Biol 211:3712-3719

Haren A (2007) Reducing noise pollution from commercial shipping in the Channel Islands National Marine Sanctuary: a case study in marine protected area management of underwater noise. J Int Wildl Law Policy 10: 153-179

Hatch LT, Fristrup KM (2009) No barrier at the boundaries: implementing regional frameworks for noise management in protected natural areas. Mar Ecol Prog Ser 395: 223-244

Hatch L, Clark C, Merrick R, Van Parijs S and others (2008) Characterizing the relative contributions of large vessels to total ocean noise fields: a case study using the Gerry E. Studds Stellwagen Bank National Marine Sanctuary. Environ Manage 42:735-752

* Heitmeyer RM, Wales SC, Pflug LA (2003) Shipping noise predictions: capabilities and limitations. Mar Technol Soc J 37:54-65

Herman LM (2017) The multiple functions of male song within the humpback whale (Megaptera novaeangliae) mating system: review, evaluation, and synthesis. Biol Rev 92:1795-1818

Hooge PN, Carlson PR, Mondragon J, Etherington LL, Cochrane GR (2004) Seafloor habitat mapping and classification in Glacier Bay Alaska: Phase 1 \& 2 1996-2004. National Park Service, Glacier Bay National Park, AK

Houghton J, Holt MM, Giles DA, Hanson MB and others (2015) The relationship between vessel traffic and noise levels received by killer whales (Orcinus orca). PLOS ONE 10:e0140119

*Houser DS (2006) A method for modeling marine mammal movement and behavior for environmental impact assessment. IEEE J Oceanic Eng 31:76-81

Jensen AS, Silber GK (2003) Large whale ship strike database. National Oceanic and Atmospheric Administration, Silver Spring, MD

Jensen BA, Kuperman W, Porter MB, Schmidt H (2000) Computational ocean acoustics. Springer-Verlag, New York, NY

Kennedy AS, Zerbini AN, Rone BK, Clapham PJ (2014) Individual variation in movements of satellite-tracked humpback whales Megaptera novaeangliae in the eastern Aleutian Islands and Bering Sea. Endang Species Res 23: 187-195

Kipple B (2002) Southeast Alaska cruise ship underwater acoustic noise. Tech Rep NSWCCD-71-TR-2002-574, Naval Surface Warfare Center, Bremerton, WA

Kipple BM (2004a) Coral Princess underwater acoustic levels. Technical Report, Naval Surface Warfare Center, Bremerton, WA

Kipple BM (2004b) Volendam underwater acoustic levels. Technical Report, Naval Surface Warfare Center, Bremerton, WA

Kipple B, Gabriele CM (2003a) Glacier Bay Underwater Noise-August 2000 through August 2002. Tech Rep NSWCCD-71-TR-2004/521, Naval Surface Warfare Center, Bremerton, WA

Kipple B, Gabriele CM (2003b) Glacier Bay watercraft noise. Tech Rep NSWCCDE-71-TR-2003/522 prepared for Gla- cier Bay National Park and Preserve, Naval Surface Warfare Center, Bremerton, WA

Kipple B, Gabriele CM (2004) Glacier Bay watercraft noise - noise characterization for tour, charter, private and government vessels. Tech Rep NSWCCDE-71-TR2004/545 prepared for Glacier Bay National Park and Preserve, Naval Surface Warfare Center, Bremerton, WA

Laist DW, Knowlton AR, Mead JG, Collet AS, Podesta M (2001) Collisions between ships and whales. Mar Mamm Sci 17:35-75

K Laist DW, Knowlton AR, Pendleton D (2014) Effectiveness of mandatory vessel speed limits for protecting North Atlantic right whales. Endang Species Res 23:133-147

Malme CI, Miles PR, McElroy PT (1982) The acoustic environment of humpback whales in Glacier Bay and Frederick Sound/Stephens Passage, Alaska. BBN Rep No. 4848 prepared for National Marine Mammal Laboratory, Seattle, WA

*McKenna MF, Katz SL, Condit C, Walbridge S (2012) Response of commercial ships to a voluntary speed reduction measure: Are voluntary strategies adequate for mitigating ship-strike risk? Coast Manage 40:634-650

*McKenna MF, Calambokidis J, Oleson EM, Laist DW, Goldbogen JA (2015) Simultaneous tracking of blue whales and large ships demonstrates limited behavioral responses for avoiding collision. Endang Species Res 27: 219-232

Moore BCJ (1982) An introduction to the psychology of hearing, 2nd edn. Academic Press, London

NOAA (National Oceanic and Atmospheric Administration) (2016) Proposed changes to technical guidance for assessing the effects of anthropogenic sound on marine mammal hearing underwater acoustic threshold levels for onset of permanent and temporary threshold shifts. NOAA, Silver Spring, MD

Neilson JL, Gabriele CM (2006) Results of humpback whale population monitoring in Glacier Bay and adjacent waters: 2006. US National Park Service, Glacier Bay National Park and Preserve, AK

Parks SE, Clark CW, Tyack PL (2007) Short- and long-term changes in right whale calling behavior: the potential effects of noise on acoustic communication. J Acoust Soc Am 122:3725-3731

Porter MB (1992) The KRAKEN normal mode program. Report No.: NRL/MR/5120-92-6920, Naval Research Laboratory, Washington, DC

Richardson WJ, Greene CR, Malme CI, Thomson DH (1995) Marine mammals and noise. Academic Press, San Diego, CA

Ross D (1976) Mechanics of underwater noise. Pergamon Press, New York, NY

Ross D (2005) Ship sources of ambient noise. IEEE J Oceanic Eng 30:257-261

SAS Institute (2015) JMP version 12. SAS Institute, Cary, NC

Scholik-Schlomer A, Guan S, Harrison J (2009) The integration of science and policy in establishing National Marine Fisheries Service's marine mammal acoustic guidance under the Marine Mammal Protection Act. 18th Biennial Conference on the Biology of Marine Mammals, 12-16 Oct, Quebec City, p 228

Sousa-Lima RS, Clark CW (2008) Modeling the effect of boat traffic on the fluctuation of humpback whale singing activity in the Abrolhos National Marine Park, Brazil. Can Acoust 36:174-181 
Southall BL, Bowles AE, Ellison WT, Finneran JJ and others (2007) Marine mammal noise exposure criteria: initial scientific recommendations. Aquat Mamm 33:411-521

Tennessen JB, Parks SE (2016) Acoustic propagation modeling indicates vocal compensation in noise improves communication range for North Atlantic right whales. Endang Species Res 30:225-237

Trevorrow MV, Vasiliev B, Vagle S (2008) Directionality and maneuvering effects on a surface ship underwater acoustic signature. J Acoust Soc Am 124:767-778

Tyack PL (2008) Implications for marine mammals of largescale changes in the marine acoustic environment.

Editorial responsibility: Brendan Godley,

University of Exeter, Cornwall Campus, UK
J Mammal 89:549-558

Vanderlaan ASM, Taggart CT (2007) Vessel collisions with whales: the probability of lethal injury based on vessel speed. Mar Mamm Sci 23:144-156

Wild LA, Gabriele CM (2014) Putative contact calls made by humpback whales (Megaptera novaeangliae) in southeastern Alaska. Can Acoust 42:23-31

Witteveen BH, Foy RJ, Wynne KM, Tremblay Y (2008) Investigation of foraging habits and prey selection by humpback whales (Megaptera novaeangliae) using acoustic tags and concurrent fish surveys. Mar Mamm Sci 24:516-534

Submitted: January 9, 2017 ; Accepted: August 28, 2017 Proofs received from author(s): November 8, 2017 